\title{
Seismic assessment of Japanese traditional wooden structure by dynamic interaction numerical analysis of surrounding ground
}

\author{
Hisakazu SAKAI* \\ Kazuyuki IzUnO** \\ Kazunari SAKO*** \\ Takahiro ENDO**** \\ Ryoichi FUKAGAWA** \\ Kenzo ToKI*****
}

*Department of Civil and Environmental Engineering, Hosei University

**Department of Civil Engineering, Ritsumeikan University

****Department of Ocean Civil Engineering, Kagoshima University

****Nagoya Construction Division, Meiko Construction Co., Ltd.

*****Institute of Disaster Mitigation for Urban Cultural Heritage, Ritsumeikan University

(Received September 10, 2013 Accepted March 17, 2014)

\begin{abstract}
We conducted seismic evaluations of a traditional wooden building using threedimensional earthquake response analyses. The building is registered as one of the "Historic Monuments of Ancient Kyoto”, UNESCO World Heritage Site, and is located in a region of strong earthquake motion from a scenario earthquake. The structure is an invaluable asset, but it is at risk of damage resulting from earthquake. Our numerical estimation was based on a dynamic interaction analysis between the building and the surrounding ground because it was located on the slope of a hill with complicated geophysical features. We also conducted a dynamic non-interaction analysis of the structure for a comparison with the aforementioned interaction model. Boring explorations and geotechnical tests were conducted before the assessment in order to investigate the ground foundation. We included the surrounding ground for a more realistic analysis because the seismic estimation for a model consisting only of the main structure differs significantly from that of the structureground coupling model. The results showed that the main wooden building was at risk of partial damage as it exceeded the safety limits prescribed for a scenario earthquake, and would collapse in the case of double the amplitude of the scenario earthquake.
\end{abstract}

Keyword: seismic estimation, earthquake response analysis, traditional wooden structure, scenario earthquake, soil-structure interaction. 


\section{INTRODUCTION}

In Japan, a large number of traditional wooden buildings have managed to escape many natural and artificial disasters, and most of them are concentrated in the Kinki region, situated in the western region of Honshu, the main Japanese island. The Central Disaster Management Council of Japan (2008.2) reports that many of these cultural heritage buildings are located in regions that have strong ground motion. Recently, many studies on seismic assessments of traditional wooden structures in Japan have been performed. Fujita et al. (2004) discussed the vibration characteristics of a newly built traditional timber pagoda based on the results of earthquake monitoring and micro tremor measurements. Fujita et al. (2008) conducted analyses for shaking table tests conducted for a traditional timber pagoda in 2004-2006. Mori et al. (2007) showed the effect of axial force fluctuation of supporting columns for the seismic performance of the main wooden building of this study by conducting three-dimensional nonlinear earthquake response analyses. Suzuki et al. (2007) examined the effect of a stage on the earthquake response of the traditional structure and showed that non-rigid floor assumption affects the response of the stage of the structure.
However, these studies estimated the seismic performance of a traditional wooden structure with a model consisting of only the building. This seems to be particularly important for a traditional wooden building with a stage on the slope of a hill located in complex topography. Toki et al. (2013) examined the performance based on the dynamic structure-ground interaction. However, the response of the main structure must be estimated with higher frequency than the actual response, because they used the linear stressstrain model for the structure and the perfectly elastoplastic constitute model for the surrounding soil. Therefore, we conducted non-linear three-dimensional numerical simulations for the building during scenario earthquakes using a non-linear constitute model for the structure and the Ramberg-Osgood type curvilinear model for the ground.

\section{IN-SITU INVESTIGATION}

The main building with a wooden stage is located on the slope at the foot of a mountain and in complex topography as mentioned above, and there are several stone masonry walls around the building (see Fig.1). We conducted three boring investigations around the main building at the locations of B1, B2

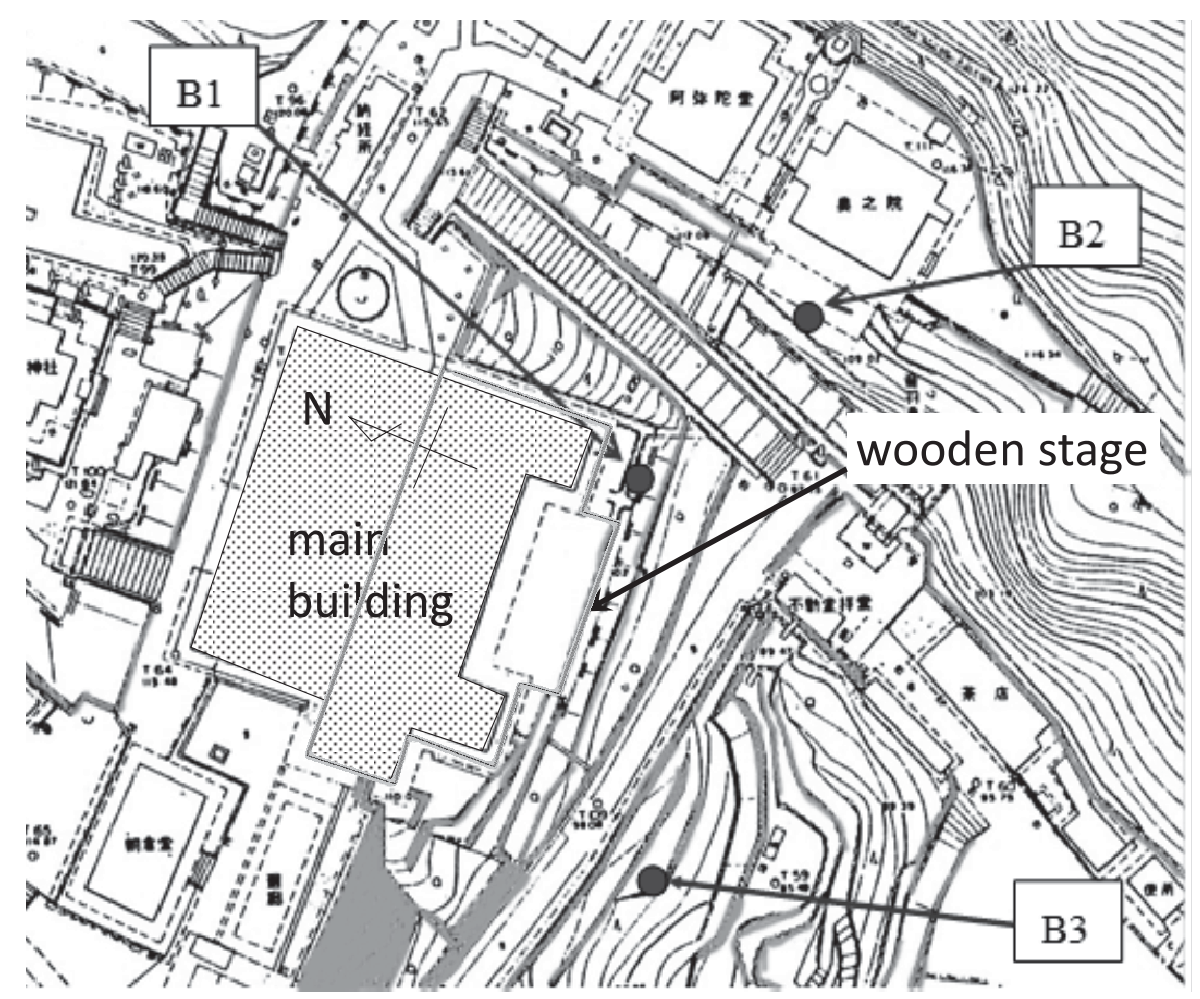

Figure 1. Positions of boring investigations. Stone masonry walls are indicated by the gray area. 
and B3 shown in Fig.1. The standard penetration tests were conducted at each borehole. Figs.2-4 show the boring logs obtained from these examinations. The investigations at B1 were conducted on the slope under the main wooden stage of the building. The $\mathrm{N}$ values for B1 were greater than 60 at the soil layer more than $10 \mathrm{~m}$ below the surface, and the ground water surface existed at a depth of $5.5 \mathrm{~m}$ below the

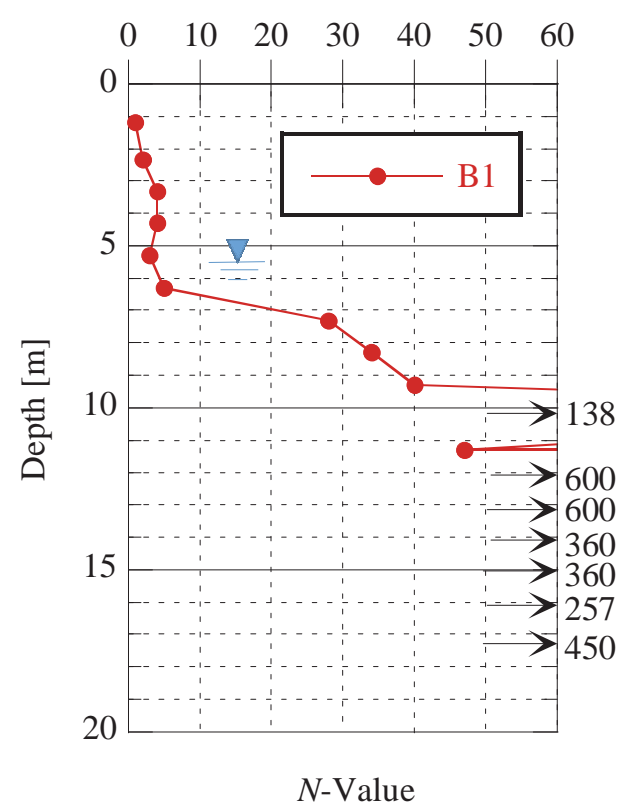

Figure 2. The result of standard penetration test at B1.

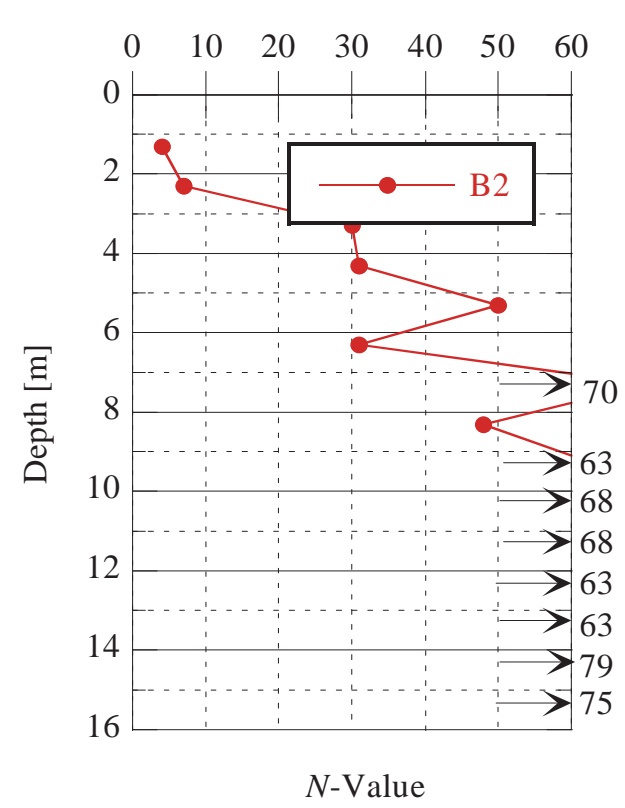

Figure 3. The result of standard penetration test at B2. ground surface. Laboratory soil tests using the boring core were also conducted to estimate the soil properties at B1. Soil particle density, grain size distribution, classification of geomaterials, and consistency are listed in Table 1. A standard penetration test at B2 showed that the $\mathrm{N}$-Values are greater than 50 at the soil layer more than $7 \mathrm{~m}$ below the surface, and the ground at B2 seemed relatively stable. There is no ground water surface at B2. The point B3 of the boring investigation and standard penetration test was located on the lower part of the slope on which the main structure stood. The N-Values of B3 were less than 30 in most layers, and the bedrock did not appear in the boring core. Based on these in-situ investigation results (see Architectural Research Association: Report of survey of existing circumstances at main building of Kiyomizu temple and 8 other buildings (2007) for more information) and laboratory soil tests, the parameters of numerical simulation were estimated.

\section{METHODOLOGY}

We evaluated the safety of the main traditional wooden building based on three-dimensional finite element method (FEM) analysis (SoilPlus, CTC, ITOCHU Techno-Solutions Corporation, Japan), which used the 3D elements of ground and structure with non-linear properties. In addition, we compared the

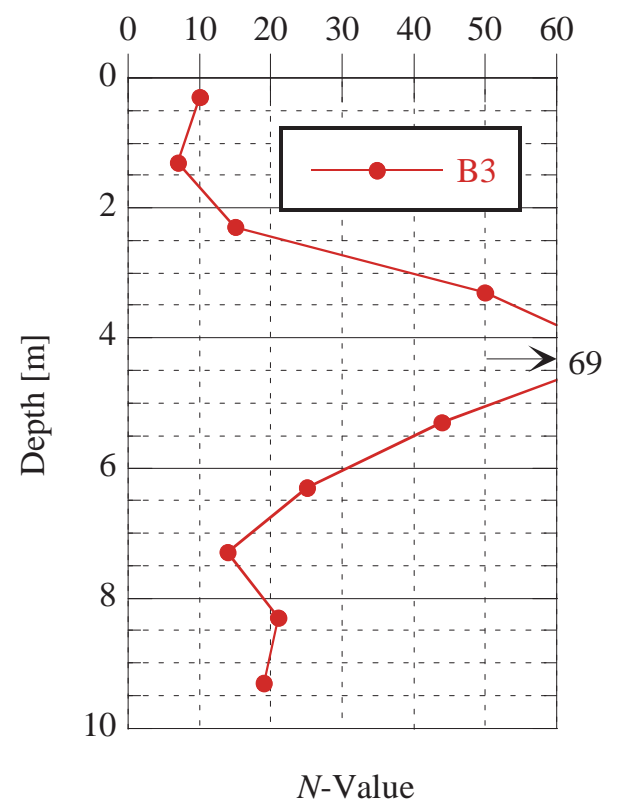

Figure 4. The result of standard penetration test at B3. 
Table 1. Soil properties of boring core obtained at No. B1 in

\begin{tabular}{|c|c|c|c|c|c|}
\hline No. & 1 & 2 & 3 & 4 & 5 \\
\hline Depth [G.L.-m] & $2.15-2.55$ & $4.15-4.45$ & $6.15-6.45$ & $8.15-8.45$ & $11.15-11.45$ \\
\hline Soil particle density $\left[\mathrm{g} / \mathrm{m}^{3}\right]$ & 2.577 & 2.623 & 2.655 & 2.663 & 2.653 \\
\hline Natural water content [\%] & 51.3 & 30.1 & 18.7 & 11.8 & 14.3 \\
\hline \multicolumn{6}{|l|}{ Grain size distribution } \\
\hline Gravel fraction [\%] & 21.9 & 35.9 & 30.0 & 6.6 & 6.7 \\
\hline Sand fraction $[\%]$ & 27.2 & 29.9 & 37.4 & 54.7 & 52.2 \\
\hline Silt fraction [\%] & 32.0 & 25.4 & 16.9 & 26.6 & 21.2 \\
\hline Clay fraction [\%] & 18.9 & 8.8 & 15.7 & 12.1 & 19.9 \\
\hline Uniformity coefficient & - & 227.68 & - & 147.96 & - \\
\hline Coefficient of curvature & - & 0.33 & - & \begin{tabular}{|l|}
0.99 \\
\end{tabular} & - \\
\hline \multirow[t]{2}{*}{ Classification of geomaterials } & Sandy and gravelly clay & Cohesive sandy gravel & Cohesive gravelly sand & Cohesive sand including gravel & Cohesive sand including gravel \\
\hline & CLSG & GCsS & SCsG & SCs-G & SCs-G \\
\hline \multicolumn{6}{|l|}{ Consistency } \\
\hline Liquid limit WL [\%] & 40.1 & - & - & - & - \\
\hline Plastic limit WP [\%] & 22.9 & - & - & - & - \\
\hline Plasticity index & 17.2 & - & - & - & - \\
\hline
\end{tabular}

results from the analysis of a model consisting only of the building (structure model) with that of a structure and ground coupling model (coupling model) in order to propose an appropriate methodology for a seismic assessment of a valuable structure located in complex topography.

\subsection{Analytical model}

\section{(1) Main traditional wooden building}

The main wooden structure with the stage was constructed on the slope at the hill. Forty- eight tall and short columns support the overhanging part of the stage. The area of the structure is about $1170 \mathrm{~m}^{2}$, the height of the main building is about $18 \mathrm{~m}$, and the height of the stage is about $13 \mathrm{~m}$ at the tallest support column point. The structure had been reconstructed in
1633 following a fire (see Fig.5). Suzuki et al. (2007) conducted a field investigation, and clarified the profiles, section size of the support columns, clay walls, slabs and penetrating beams, and plain and side view. The plain and section views are shown in Figs. 6 and 7, and the analytical FE model is shown in Fig.8. We assumed that the columns, penetrating beams and slabs are linear beams, column feet, penetrating tie beams and joints are nonlinear rotational and horizontal springs, and substitute clay walls, stage floor and roof are linear braces. Japanese cypress was used for the stage floor; for the others, a type of zelcova was used. The elastic and shear modulus of the cypress were $5880 \mathrm{~N} / \mathrm{mm}^{2}$ and $390 \mathrm{~N} / \mathrm{mm}^{2}$, and those of zelcova were $8800 \mathrm{~N} / \mathrm{mm}^{2}$ and $590 \mathrm{~N} / \mathrm{mm}^{2}$, respectively. The nonlinear spring properties are shown in Table 1.

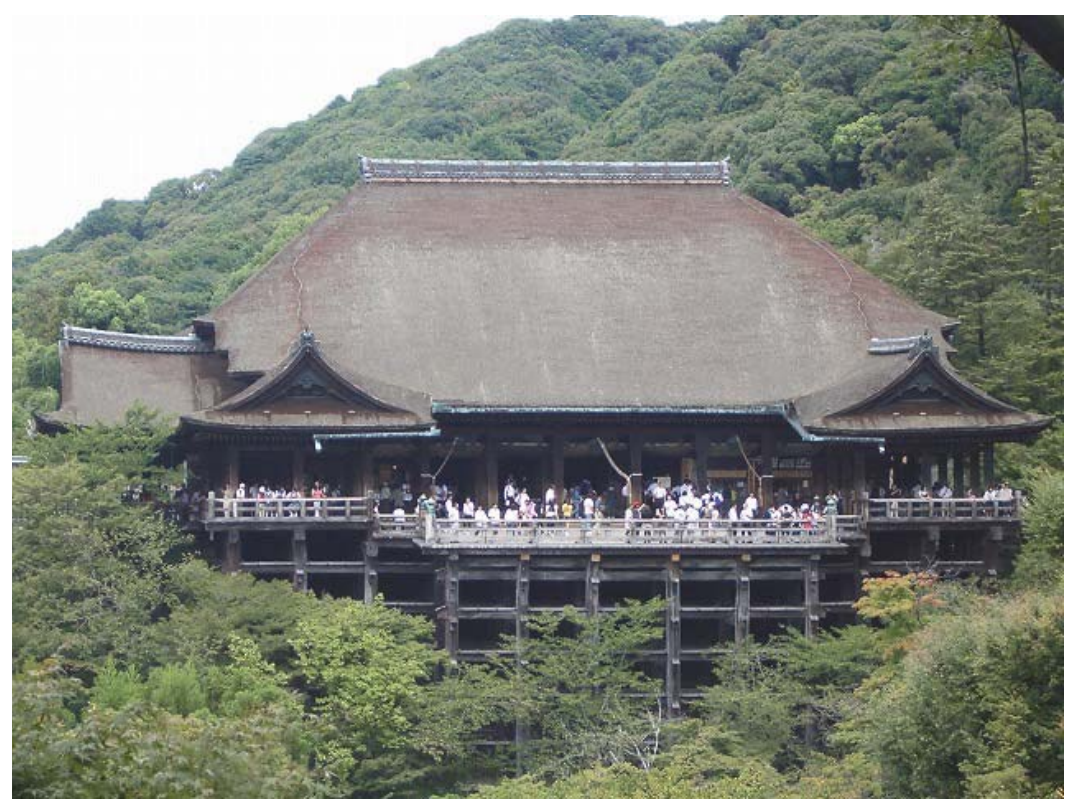

Figure 5. Main wooden structure with stage. 


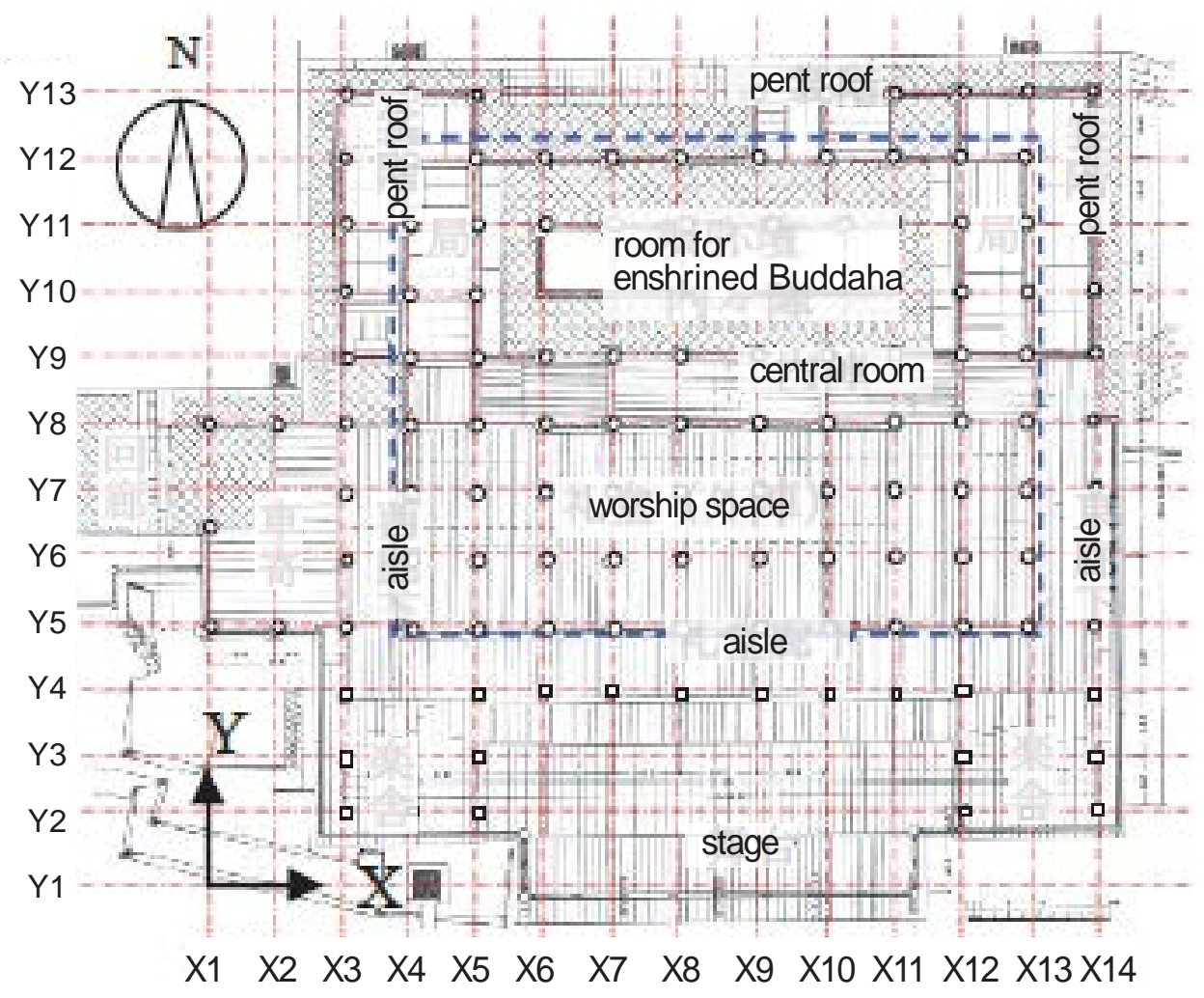

Figure 6. Plain view of the main structure.

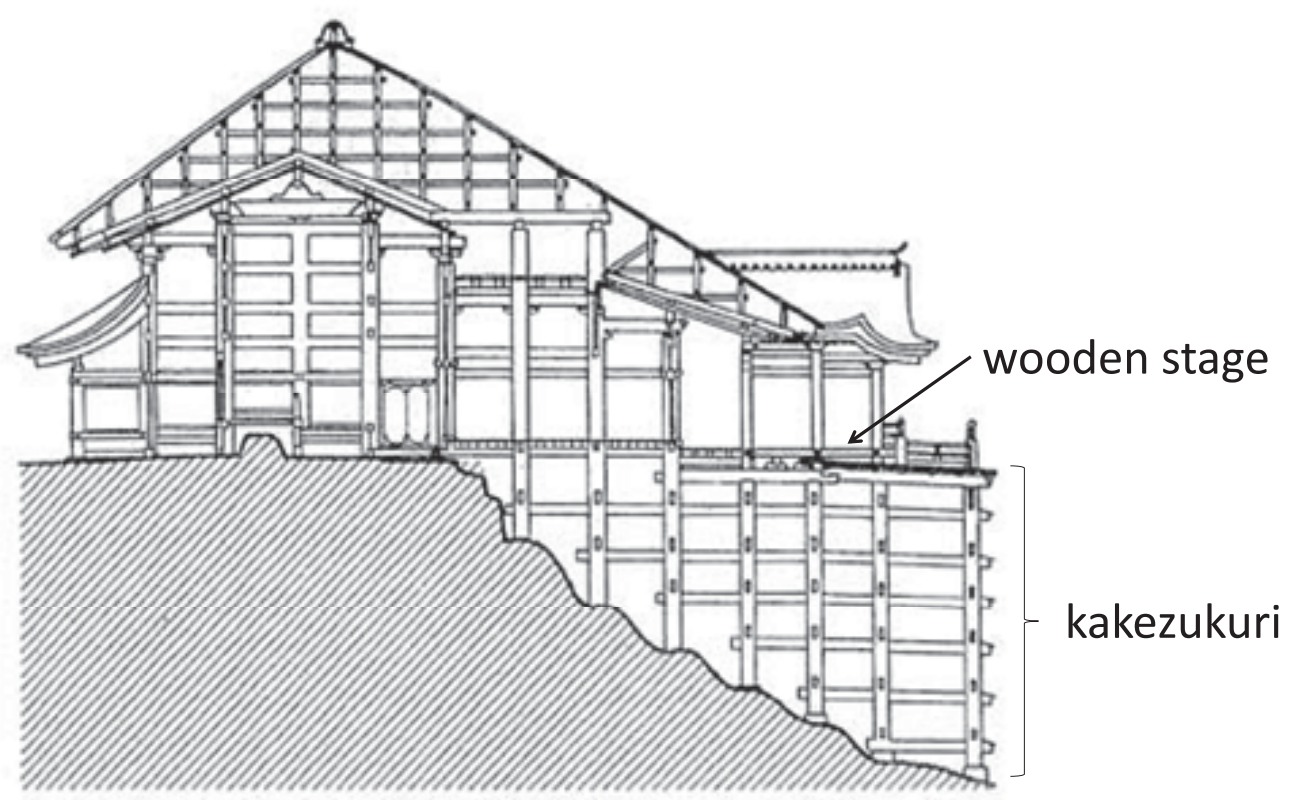

Figure 7. Section drawing of the main structure. (From AIJ: Architectural Design Data Corpus, Vol.10, Technology)

For more details of these properties, see (Suzuki et al. 2007). The appropriateness of the model was confirmed by comparing the numerical natural frequencies of the analytical model and the microtremor measurements by Suzuki et al. (2007). The first natural frequencies were $1.6 \mathrm{~Hz}$ and $1.8 \mathrm{~Hz}$ in the NorthSouth direction, and the second were $1.7 \mathrm{~Hz}$ and 1.9 $\mathrm{Hz}$ in the East-West direction, respectively. The deformation mode shapes of the structure at natural frequencies are shown in Fig.9. 


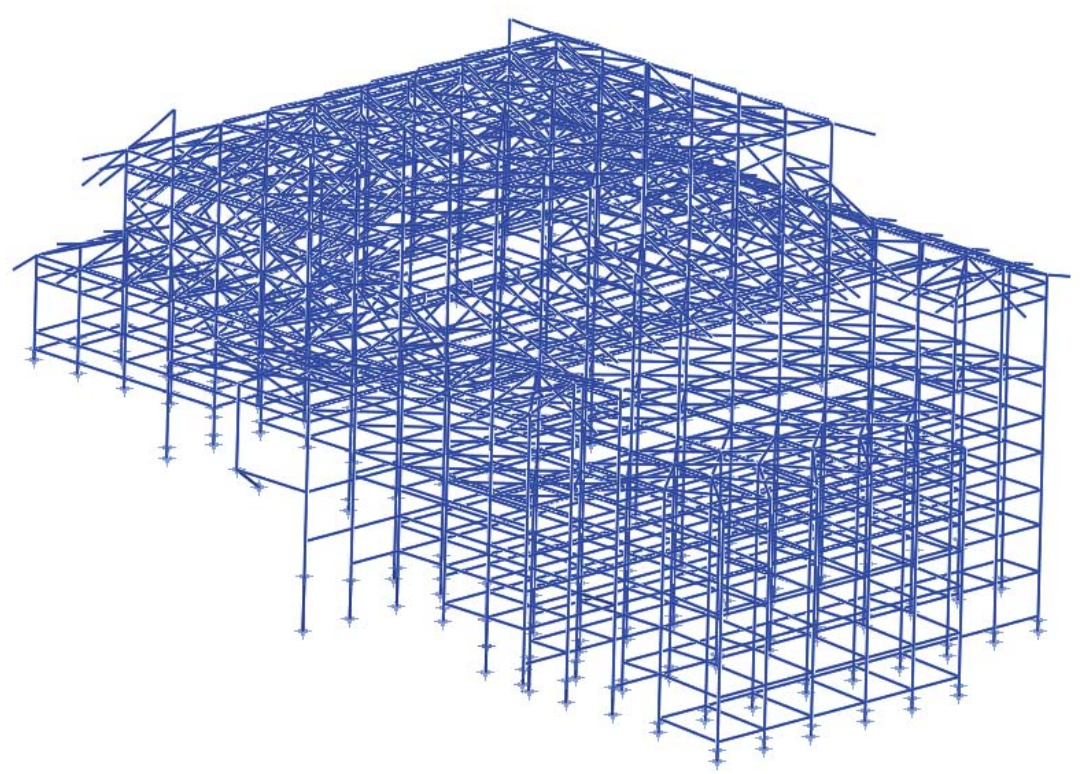

Figure 8. Finite elemental model of the main structure.

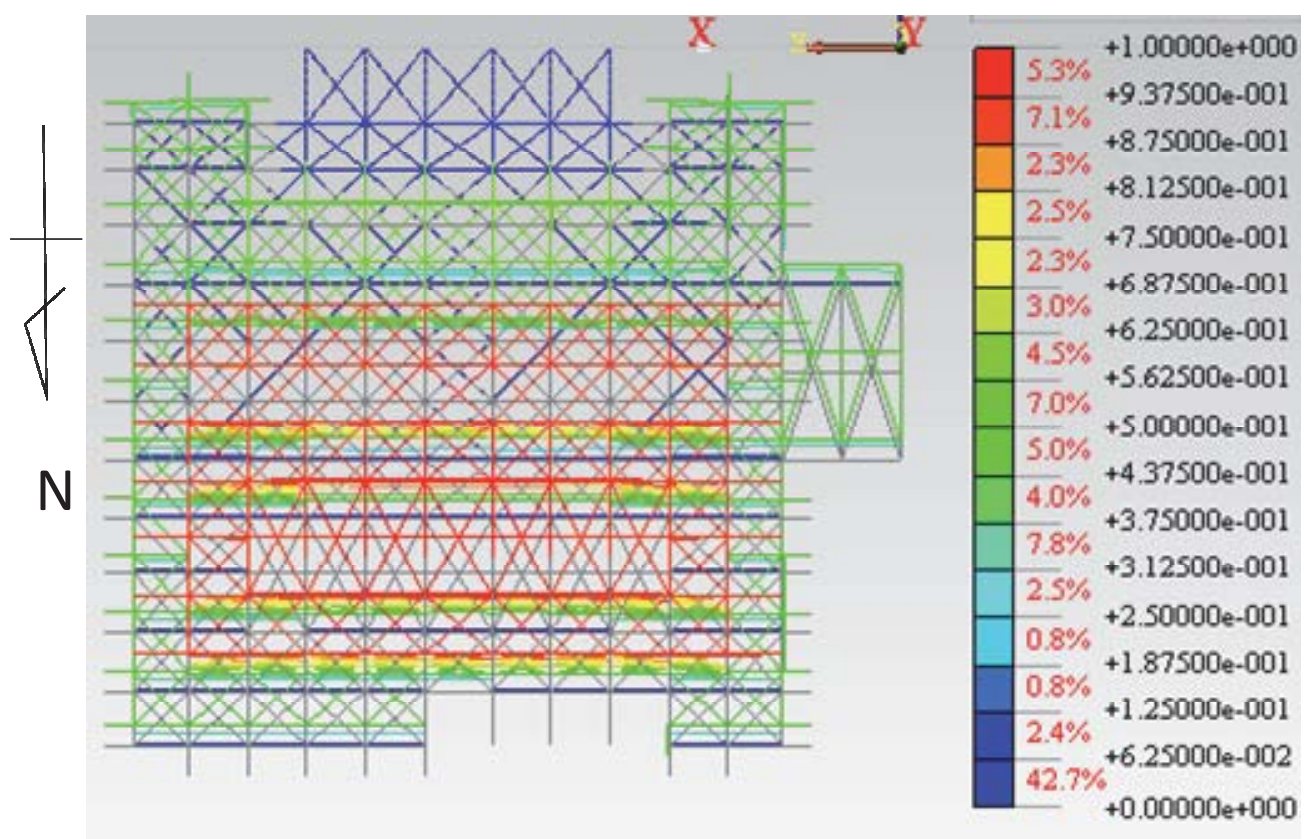

(a) The first natural deformation mode shape of the main building. The deformation mode shape trends predominantly N-S.

\section{(2) Surrounding ground}

We created the ground model for the shallow sediments in the engineering basement. The area of the model with East-West and North-South lengths of $320 \mathrm{~m}$ and $300 \mathrm{~m}$, respectively, was more than twice the width of the main structure. S-wave velocity in the engineering basement was $750 \mathrm{~m} / \mathrm{s}$, since the input ground motion on the basement was calculated as per Toki et al. (2007) under the condition that its Swave velocity was exceeded $700 \mathrm{~m} / \mathrm{s}$ (see Fig.10). We determined the characteristics of the layers by reference to the in-situ investigation of Chapter 2 and other surveys (Kuwata, 2009; Kyoto city government, 2003). For example, the surface shear wave velocities were determined based on the results of the shallow shear wave velocity sounding by Kuwata, the internal 


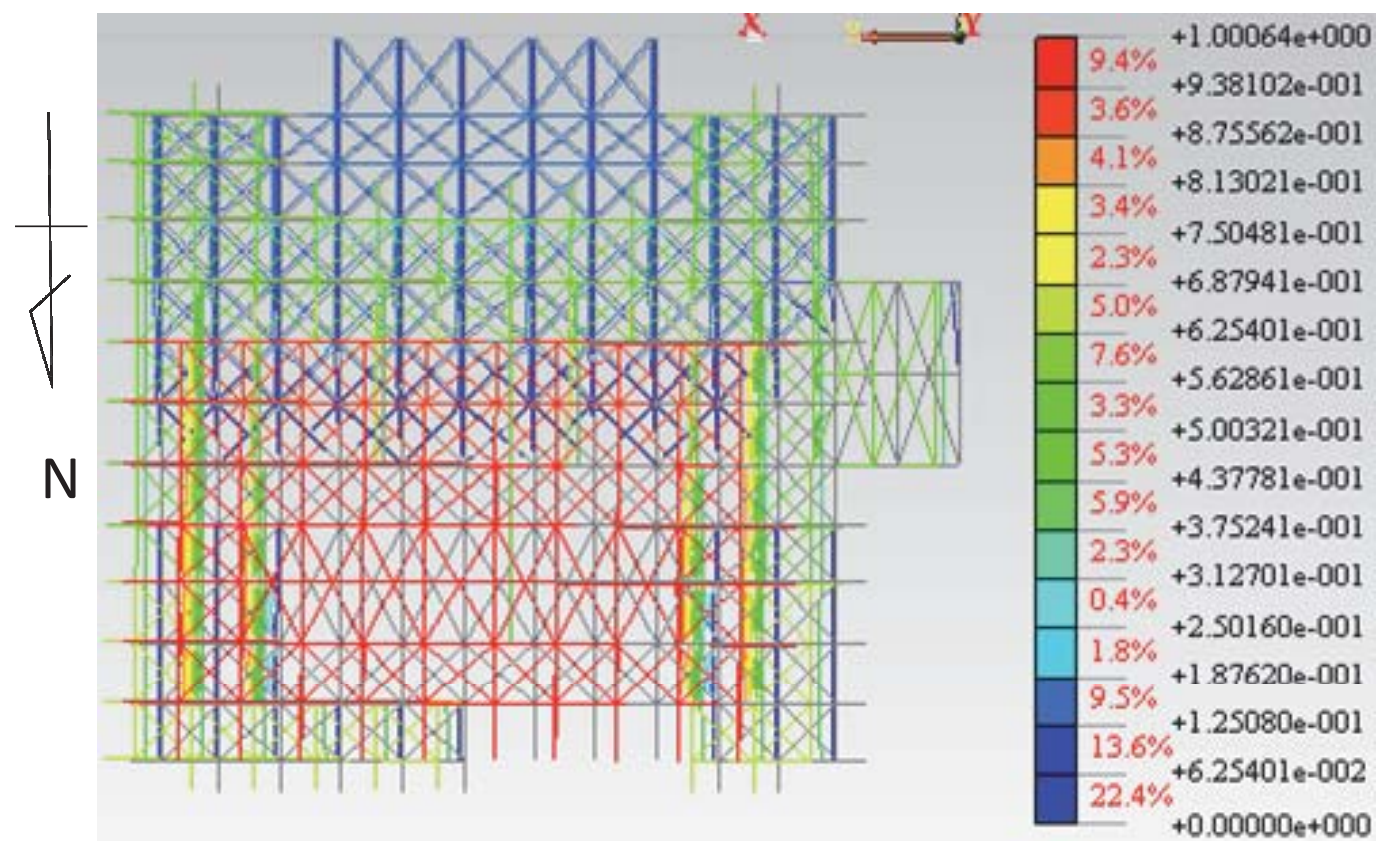

(b) The second natural deformation mode shape of the main building. The deformation mode shape trends predominantly E-W.

Figure 9. Predominant deformation mode shapes.

Table 2. Properties of nonlinear springs.

\begin{tabular}{ll}
\hline Section & Property type \\
\hline Rotation of foot of support column & Tri-linear elastic \\
Rotation between column and penetrating beam & Nonlinear elastic \\
Rotation between top of column and beam & Nonlinear elastic \\
Rotation of penetrating tie beam & Nonlinear elastic \\
Horizontal spring & Normal bi-linear \\
Horizontal spring of foot of support column & Joint element \\
\hline
\end{tabular}

friction angles, cohesions and unit weight of the surface ground were defined with the results of the laboratory test by Sako, and the deep ground structure was set based on the report by Kyoto city government. For evaluations of the ground, we consulted the results of the in-situ investigation of Chapter 2. The geological properties were classified into mountainous or nonmountainous areas as shown in Tables 3 and 4, and were applied as the Ramberg-Osgood type non-linear characteristics except elements for the stone masonry walls. Herein, tetrahedron and pentahedron elements arranged on the ground surface were also assumed as linear elasticity considering the accuracy of those elements with non-linear properties on the FEM code. The linear characteristics of the element for the stone masonry wall were calculated in proportion to the wall volume in the element.

\section{(3) Structure and ground coupling model}

As mentioned above, the main wooden building was built on a slope with a stage supported by 48 tall and short columns; hence, a different input motion should be incident for each support column. On the other hand, a dynamic interaction spring is generally used between the structure and ground in architectural seismic estimations in order to express the radiation damping as well as the effective input motion to the structure. However, the characteristics of the spring strongly influence the response solutions in spite of the difficulty of the adequacy of the data set. Due to these reasons, we adapted this coupling model for the seismic estimation of the structure. The structure is 


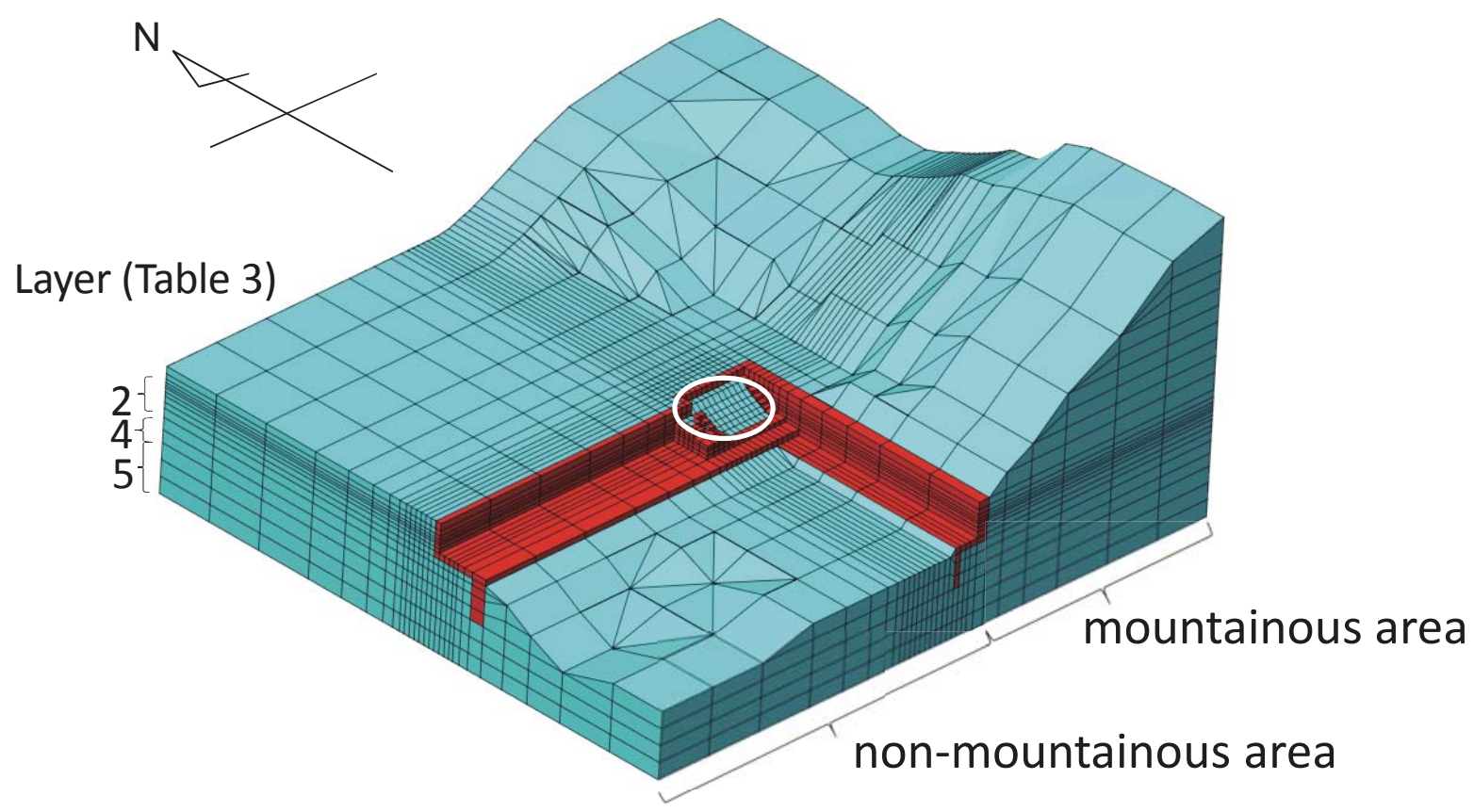

Figure 10. Surrounding ground model. Red elements indicate stone masonry walls and the high stage of the main structure is built on the slope (white ellipse at the center of the model).

Table 3. Geological properties of sediment layers of non-mountainous area.

\begin{tabular}{lllllll}
\hline Layer & $\begin{array}{l}1-1 \\
\text { (except 1-2) }\end{array}$ & $\begin{array}{l}1-2 \\
\text { (beneath stage) }\end{array}$ & 2 & 3 & 4 & 5 \\
\hline Depth $(\mathrm{m})$ & $0-6$ & $0-6$ & $6-20$ & $20-25$ & $25-38$ & $38-63$ \\
Unit weight $\left(\mathrm{kN} / \mathrm{m}^{3}\right)$ & 18.0 & 18.0 & 18.0 & 19.6 & 20.6 & 22.5 \\
S-wave velocity $(\mathrm{m} / \mathrm{s})$ & 250 & 155 & 330 & 400 & 500 & 600 \\
Poisson's ratio & 0.33 & 0.23 & 0.36 & 0.45 & 0.45 & 0.45 \\
Elastic modulus E(MN/m $\left.{ }^{2}\right)$ & 252 & 90.0 & 450 & 946 & 1550 & 2880 \\
Shear modulus $\mathrm{G}\left(\mathrm{MN} / \mathrm{m}^{2}\right)$ & 96.0 & 36.4 & 165 & 327 & 536 & 992 \\
Cohesion $\left(\mathrm{kN} / \mathrm{m}^{2}\right)$ & 0 & 0 & 0 & 5.0 & 5.0 & 5.0 \\
Friction angle $(\mathrm{deg})$. & 35 & 30 & 38 & 40 & 45 & 48 \\
\hline
\end{tabular}

Table 4. Geological properties of sediment layers of mountainous area.

\begin{tabular}{lll}
\hline Layer & 6 & 7 \\
(subsurface) & (under subsurface) \\
\hline Unit weight $\left(\mathrm{kN} / \mathrm{m}^{3}\right)$ & 17.6 & 22.5 \\
S-wave velocity $(\mathrm{m} / \mathrm{s})$ & 200 & 600 \\
Poisson's ratio & 0.33 & 0.45 \\
Elastic modulus E(MN/m²) & 195 & 2880 \\
Shear modulus $\mathrm{G}\left(\mathrm{MN} / \mathrm{m}^{2}\right)$ & 73.5 & 992 \\
Cohesion $\left(\mathrm{kN} / \mathrm{m}^{2}\right)$ & 14 & 5.0 \\
Friction angle $(\mathrm{deg})$. & 19 & 48 \\
\hline
\end{tabular}


connected to the slope of the surrounding ground model by joint elements. Figure 11 shows the main structure and ground coupling model.

\subsection{Input ground motion}

Toki et al. (2007) estimated the ground motion around the traditional structure from a scenario earthquake of the Hanaore Fault based on a three-dimen- sional earthquake response analysis with non-linear properties of the ground. We adapted the ground motions at the surface and basement for the seismic assessment of the structural model and coupling model, respectively. Both motions included two horizontal components, the E-W and the N-S directions. The four input acceleration components are shown in Figs.12 and 13. For reference purposes, the Fourier

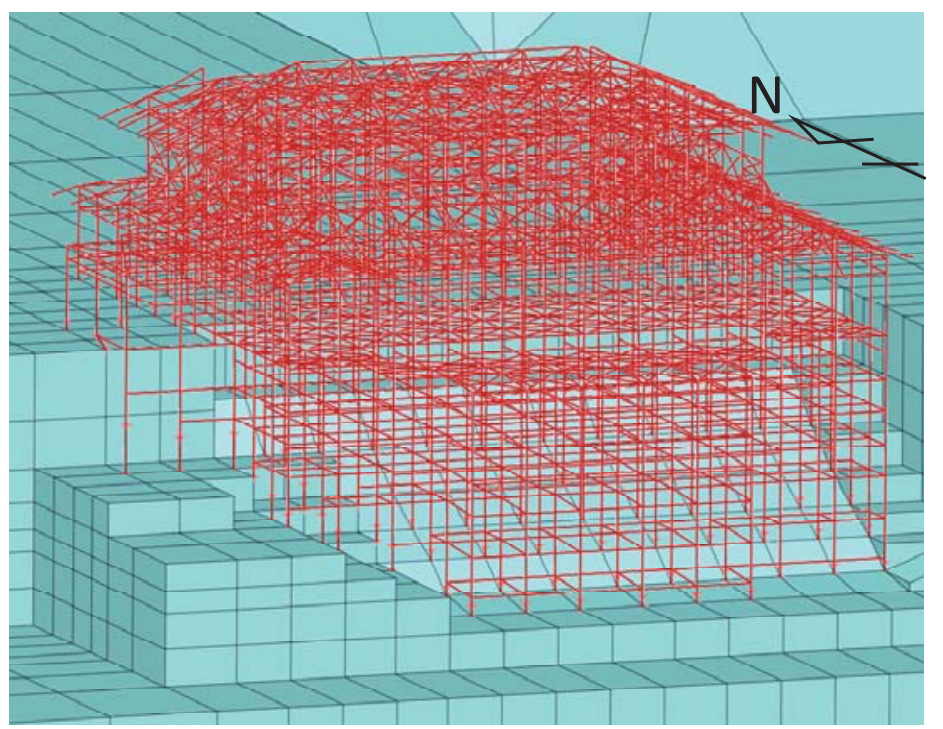

Figure 11. Main wooden structure and surrounding ground coupling model.

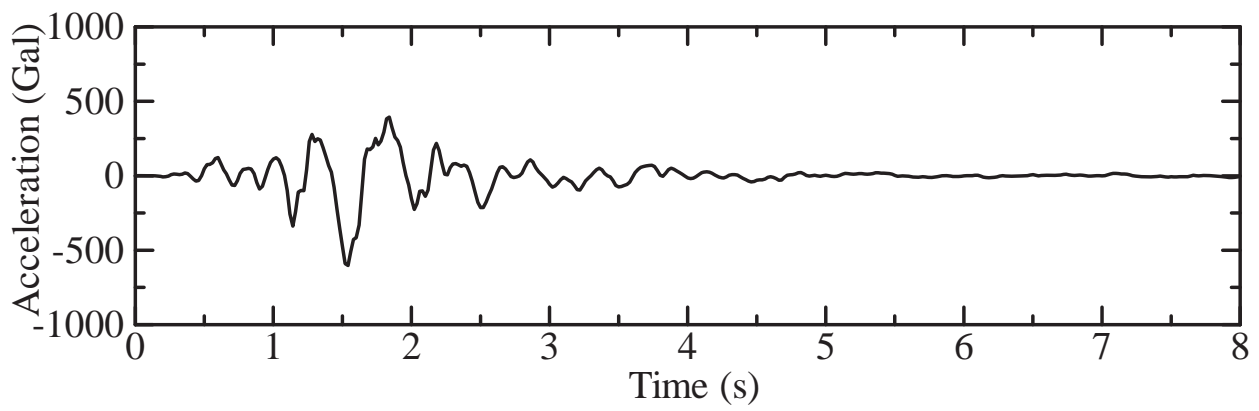

E-W component

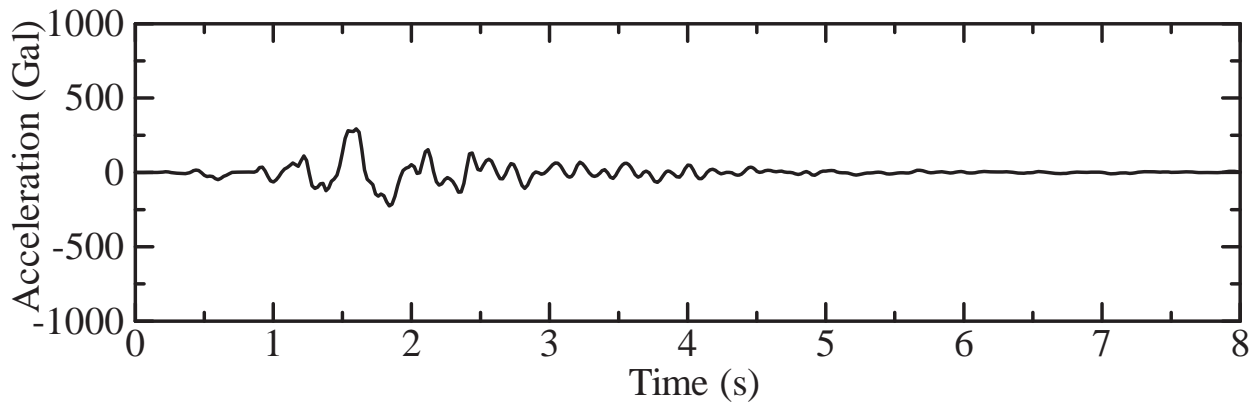

N-S component

Figure 12. Input ground motion in the basement for the structure-ground interaction model. 


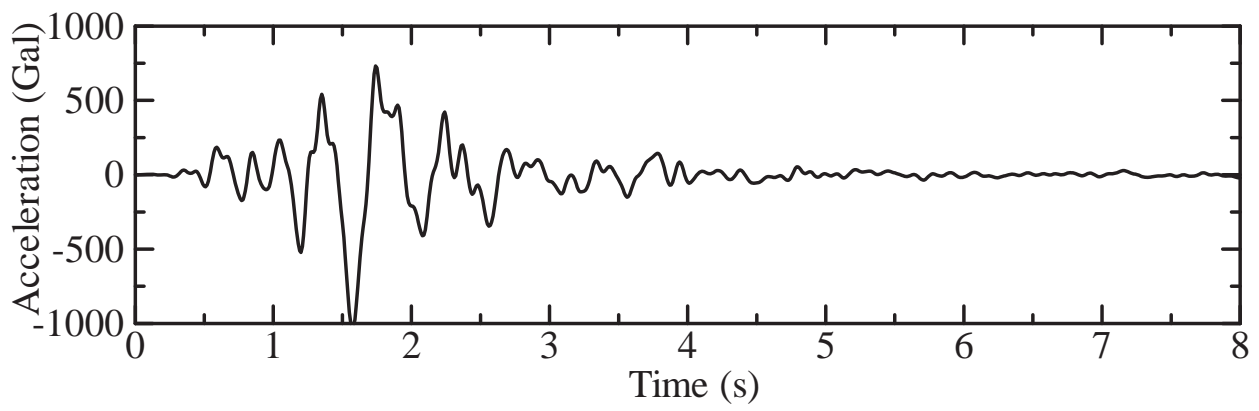

E-W component

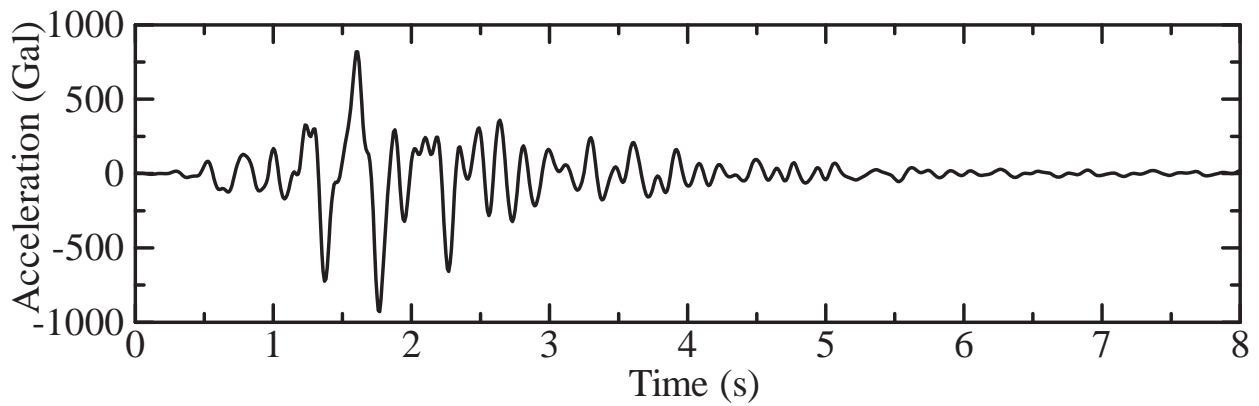

N-S component

Figure 13. Input ground motion in the basement for the structure model.

spectra of these input motions are shown in Fig.14 and 15. For the assessment of the coupling model, we assumed double the amplitude of the input ground motion in the basement as well as the original amplitude from a scenario earthquake.

The seismic evaluation for the three cases above was conducted not only to examine the safety of the main wooden structure during a scenario earthquake, but also to propose an appropriate analytical model for a structure with a stage constructed in complex topography.

\subsection{Analytical conditions}

We conducted non-linear static analysis for the structure and the coupling models before the earthquake response analysis. As some elements with elasto-plastic characteristics are subjected to the stress condition, the initial stress condition of the elements should be calculated before the dynamic response analysis. For the coupling model, the vertical slide boundaries for the four lateral faces (Eastern, Western, Northern and Southern edges of the model) were adapted for static analysis and the horizontal faces for dynamic analysis, and the bottom face was a rigid boundary for static analysis and viscous boundary for dynamic analysis, respectively. Meanwhile, the foundation side of the joint element arranged at the foot of the support column is pin support for the initial stress and the dynamic analysis. In adapting the stiffness proportional damping characteristic for the earthquake response analysis, the damping factor of elastic soil elements was equal to $15 \%$ and that of elasto-plastic elements was $2 \%$ for the fundamental mode. The Newmark-beta method (beta $=1 / 4$ ) was used to solve equations of motions for a total analytical time of eight seconds with a time interval of 2/1,000 seconds.

\section{SEISMIC ASSESSMENT FOR MAIN WOODEN STRUCTURE BASED ON EARTHQUAKE RESPONSE ANALYSIS}

\subsection{Structure model}

First, we estimated the damage of the main wooden structure during the scenario earthquake based on the earthquake response analysis for the structure model generally used for architectural seismic assessment. We focused the responses on two sites: the front edge of the stage (X8Y1 in Fig.6) and the top of the support column at the center of the main building (X8Y8 in Fig.6), and the distribution of ab- 


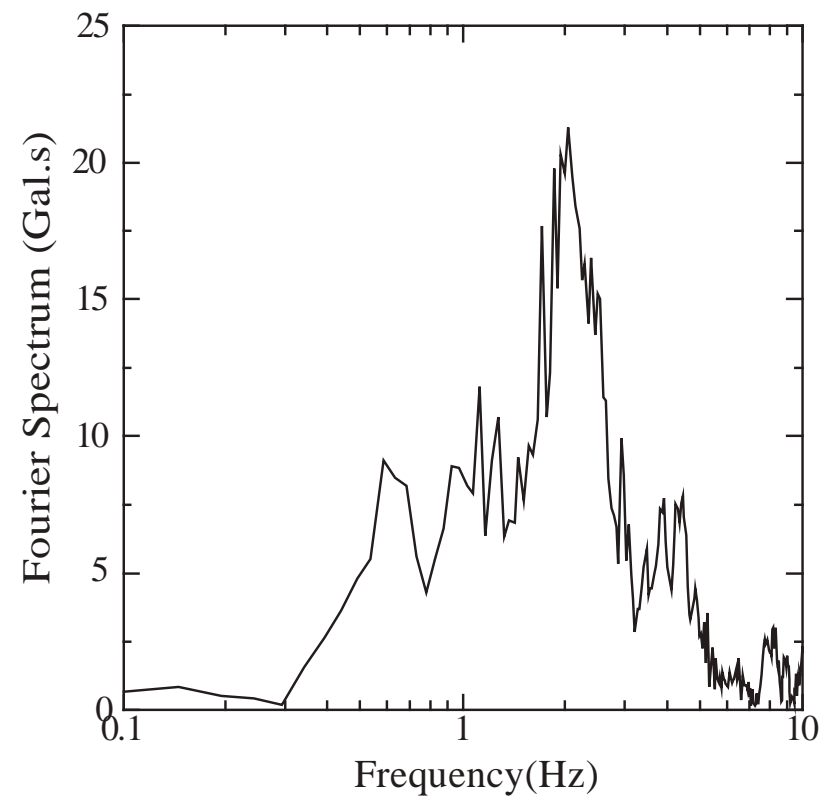

E-W component

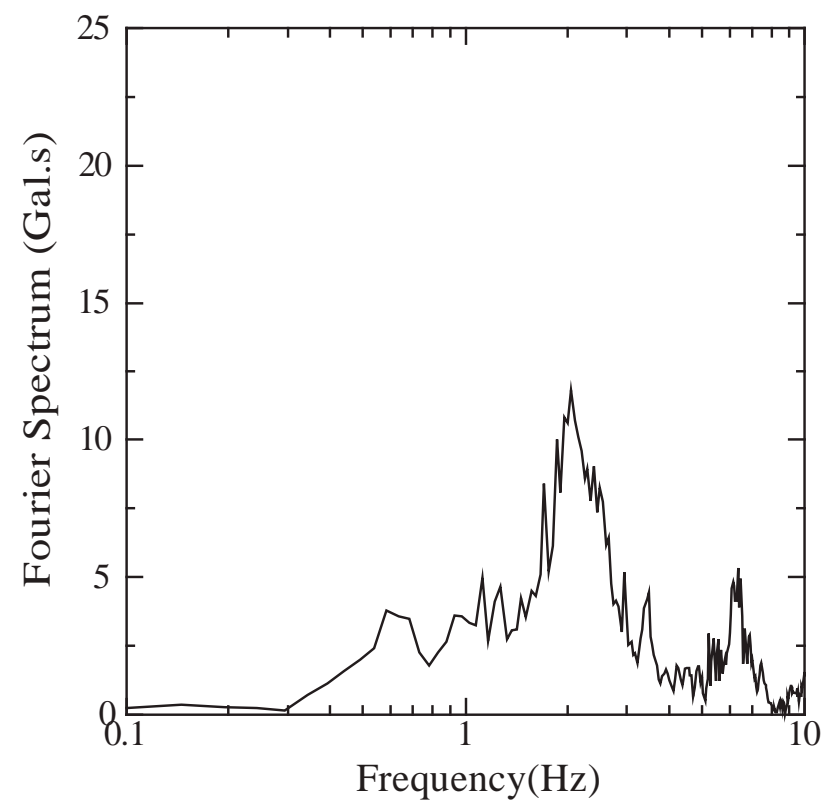

N-S component

Figure 14. Fourier spectra of the input ground motion at the basement for the structure-ground interaction model.

solute peak acceleration, and compared them with those of another case mentioned in Section 4.2. The two absolute peak values are shown in Table 5, and the distribution of the acceleration component of E-W and N-S directions is shown in Fig.16. As shown in Table 5 and Fig.16, we found that the main wooden structure responded heavily; the peak accelerations of both components of E-W and N-S directions exceeded $1 \mathrm{G}$ at the stage, and with respect to E-W components at the top support column of the main structure, the peak response velocity and acceleration exceeded 100 kine and $1 \mathrm{G}$, respectively. The N-S components of response displacement and velocity are significantly small at the front edge of the stage. This is because the stage is almost the same level as the floor of the main hall whose support columns are anchored to the fixed points. The deformations of expansion and contraction of the stage are very slight because the stage 


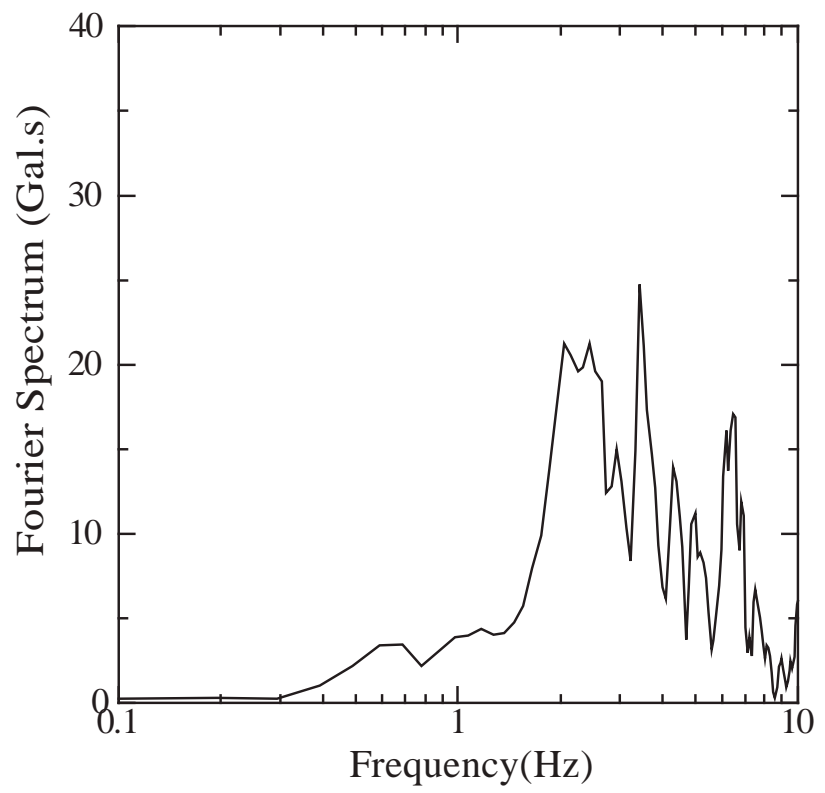

E-W component

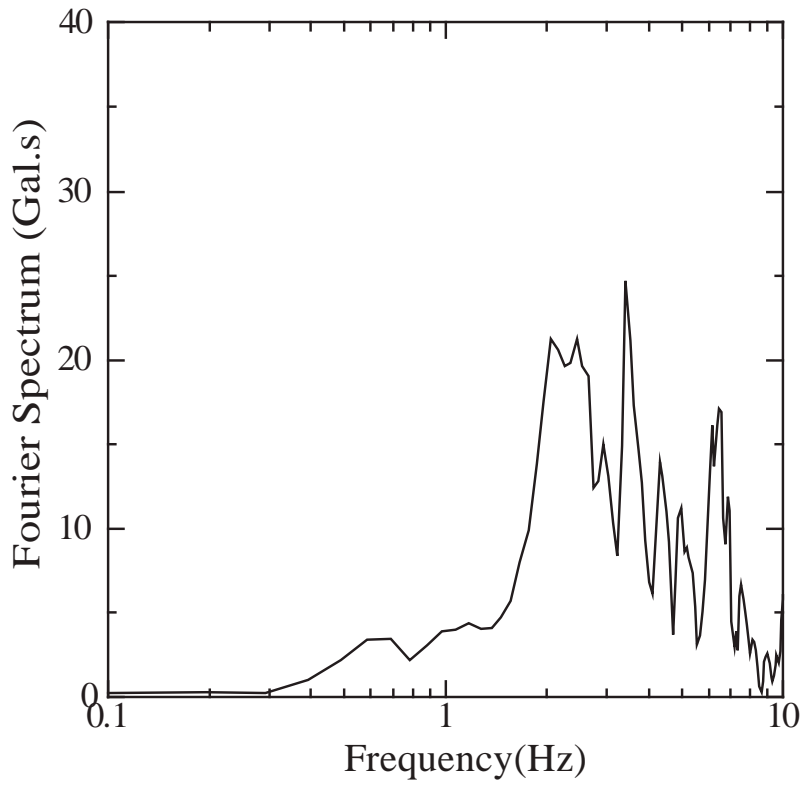

N-S component

Figure 15. Fourier spectra of the input ground motion at the basement for the structure model.

Table 5. The absolute peak response values at the front edge of the stage and the top of the support column at the center of the main wooden structure.

\begin{tabular}{lcccccc}
\hline & \multicolumn{3}{c}{ Front edge of the stage } & \multicolumn{3}{c}{ Top of support column } \\
\hline Directional component & E-W & N-S & U-D & E-W & N-S & U-D \\
Displacement (cm) & 3.8 & 0.4 & 0.002 & 13.7 & 5.9 & 0.005 \\
Velocity (kine) & 52.1 & 9.5 & 0.04 & 144 & 61.5 & 0.1 \\
Acceleration (Gal) & 1528 & 1331 & 1.4 & 1249 & 733 & 5.6 \\
\hline
\end{tabular}




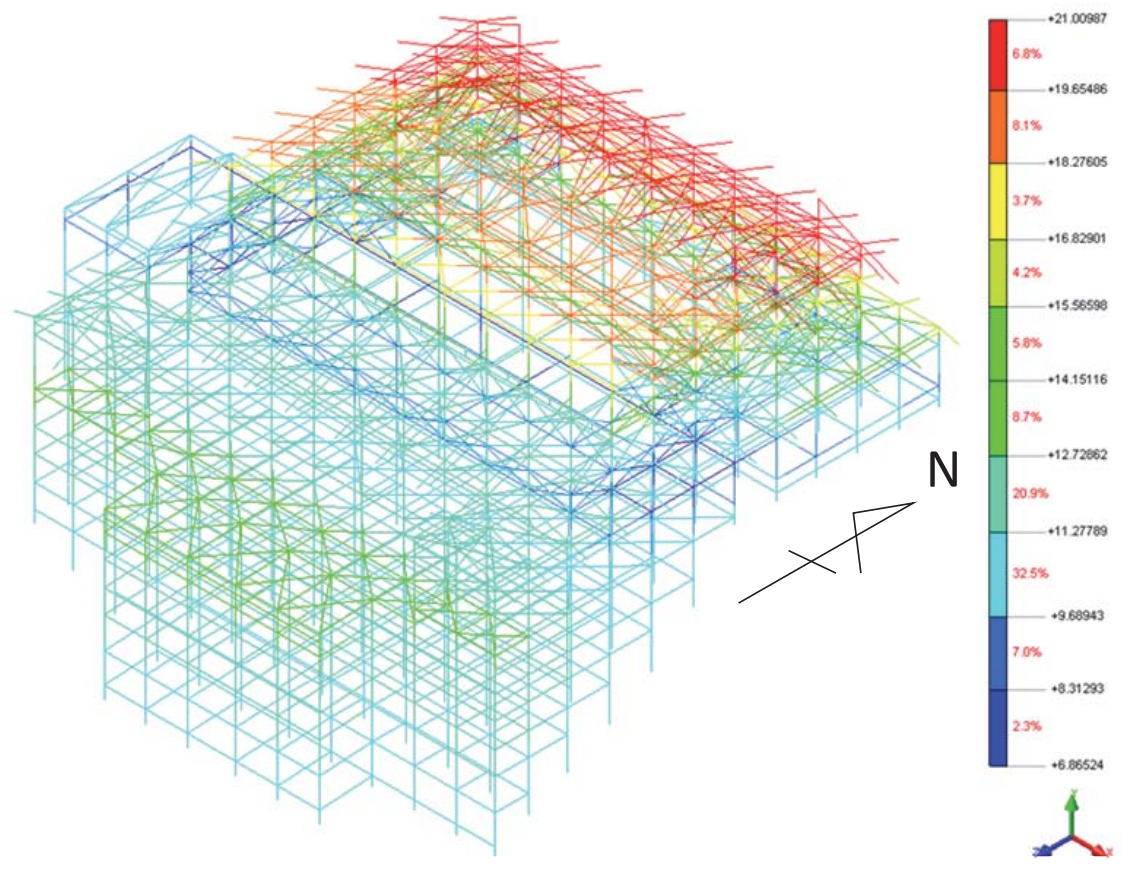

E-W directional component

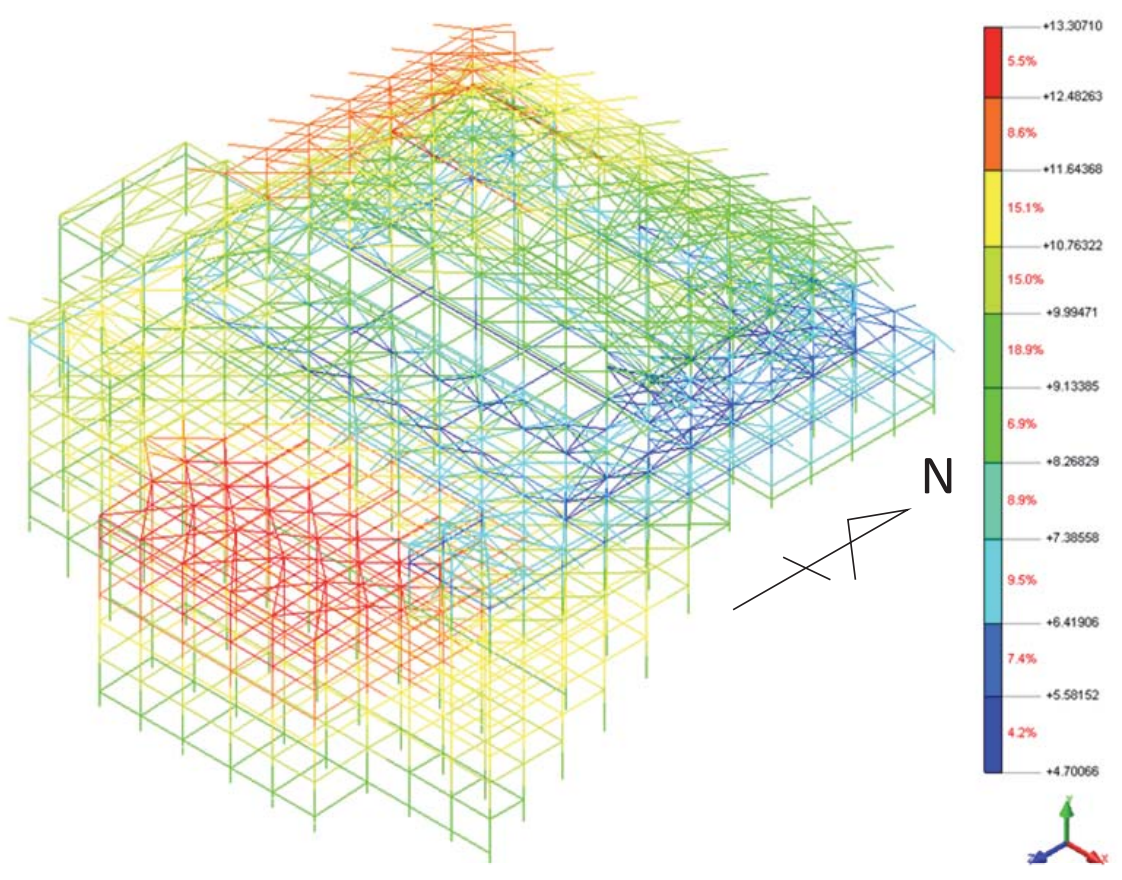

N-S directional component

Figure 16. Distribution of absolute peak response acceleration of the main wooden structure (Unit: $\mathrm{m} / \mathrm{s}^{2}$ ).

was built as a plate structure. Therefore, the movement of N-S direction of the stage is controlled by the floor of the main hall. Herein, a frequency of about $1.8 \mathrm{~Hz}$ was outstanding at the top of the support column in both horizontal components, and a frequency from $2.5-4 \mathrm{~Hz}$ and frequencies of $2 \mathrm{~Hz}, 3.5 \mathrm{~Hz}$ and $6.5 \mathrm{~Hz}$ were dominant in E-W and N-S components at the front edge of the stage, respectively. For reference purposes, the distribution of the displacement component of E-W and N-S directions is shown in Fig.17.

\subsection{Coupling model}

In this section, we conducted the seismic assessment for the main historic building based on the cou- 


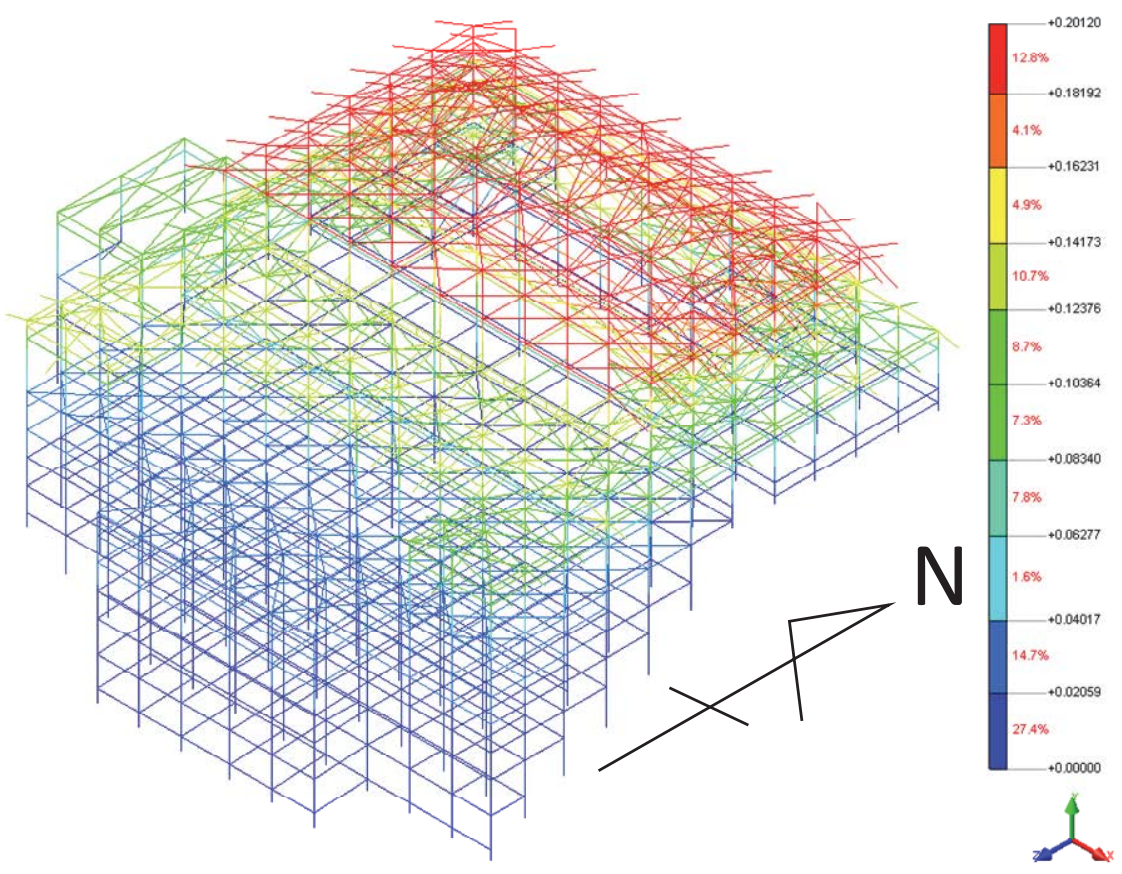

E-W directional component

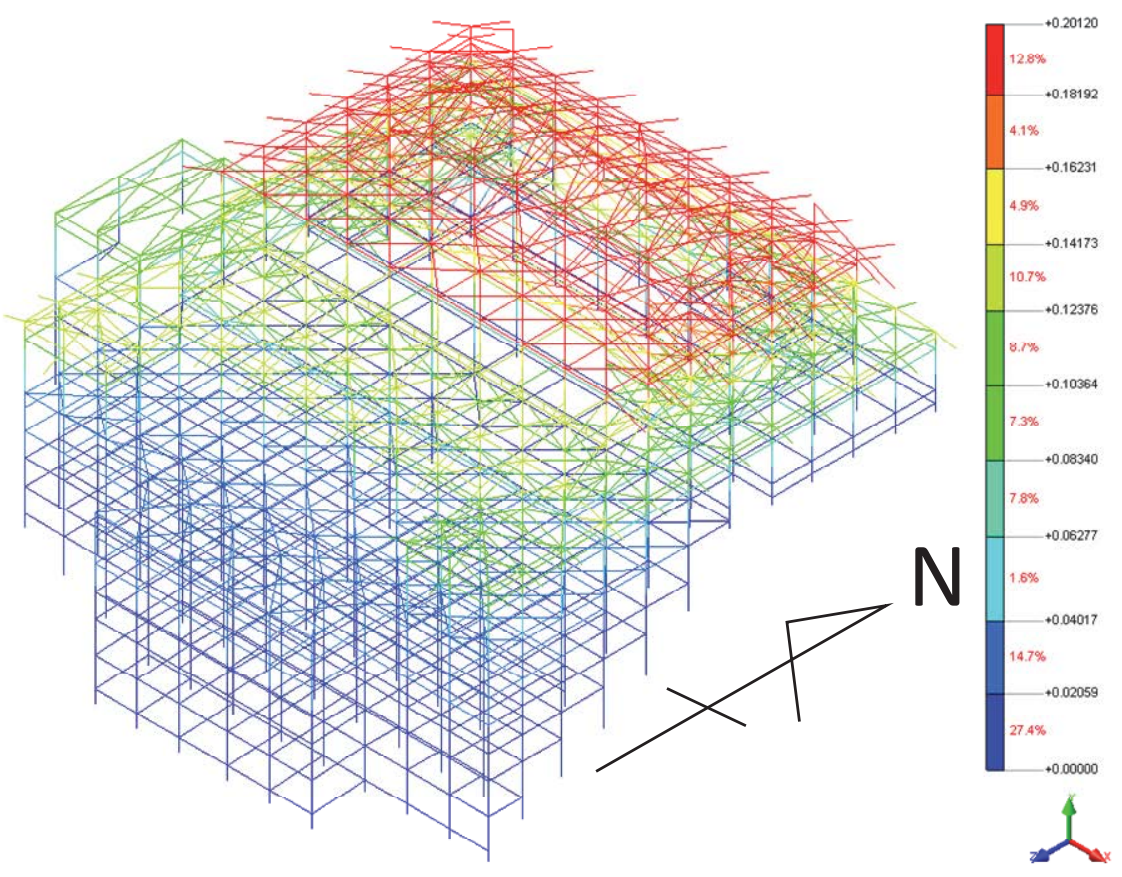

N-S directional component

Figure 17. Distribution of peak response displacement of the main wooden structure (Unit: m).

pling model. The results of the earthquake response analyses are shown in Table 6 and Fig.18.

As shown in Tables 5 and 6, the E-W and N-S components of the response acceleration of the coupling model at the center of the top column exceed 1 $\mathrm{G}$ and are larger than those of the structure model. The reason is that the building stands at the foot of the mountain and the response accelerations at the location of the main building are amplified on behalf of the ground with the three-dimensional irregular interface. In contrast, at the front of the stage, the response accelerations of the coupling model are smaller than those of the structure model. This is attributed to the phase difference of the input motion for the columns 
Table 6. The absolute peak response values at the front edge of the stage and the top of the support column at the center of the main wooden structure. (Single amplitude)

\begin{tabular}{lcccccc}
\hline & \multicolumn{3}{c}{ Front edge of the stage } & \multicolumn{3}{c}{ Top of support column } \\
\hline Directional component & E-W & N-S & U-D & E-W & N-S & U-D \\
Displacement (cm) & 10.1 & 5.3 & 1.1 & 21.3 & 11.1 & 2.1 \\
Velocity (kine) & 111.3 & 60.7 & 11.9 & 171.9 & 84.6 & 25.1 \\
Acceleration (Gal) & 1307 & 691 & 293 & 1567 & 946 & 542 \\
\hline
\end{tabular}
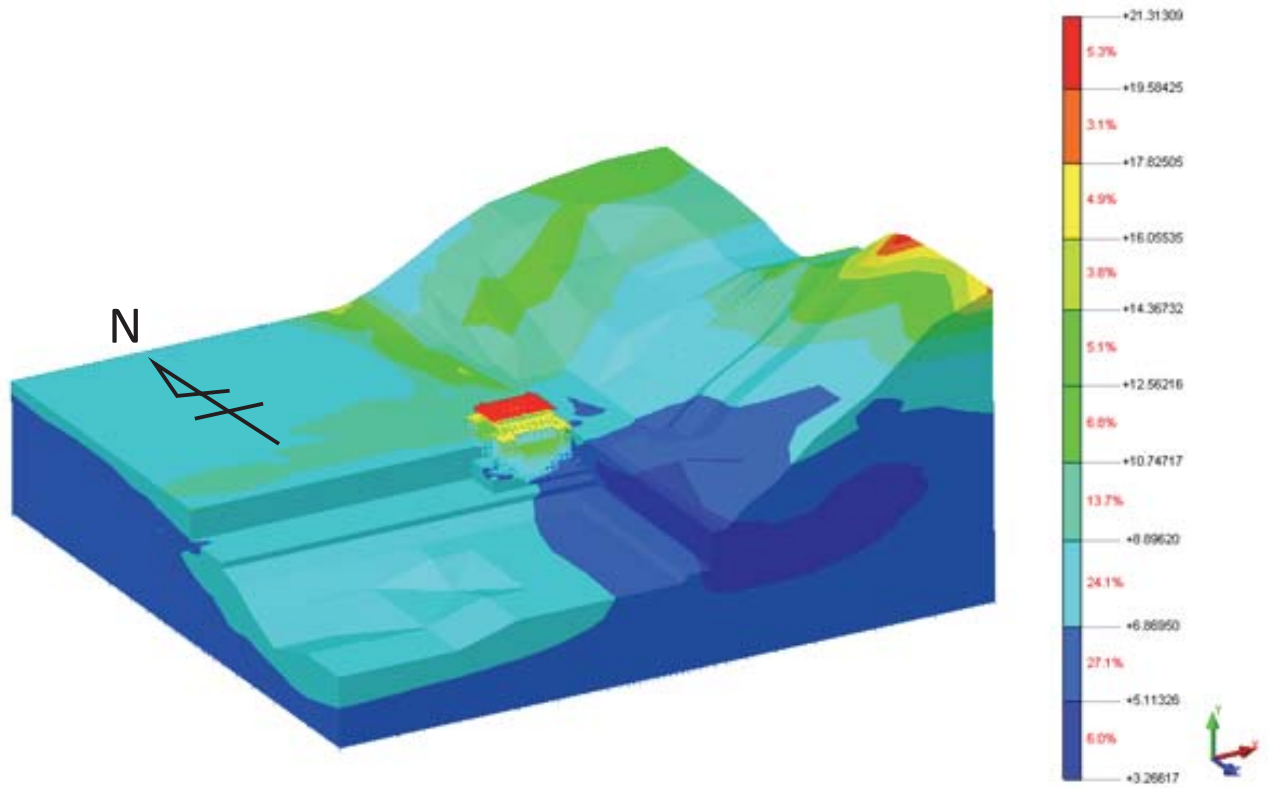

E-W directional component
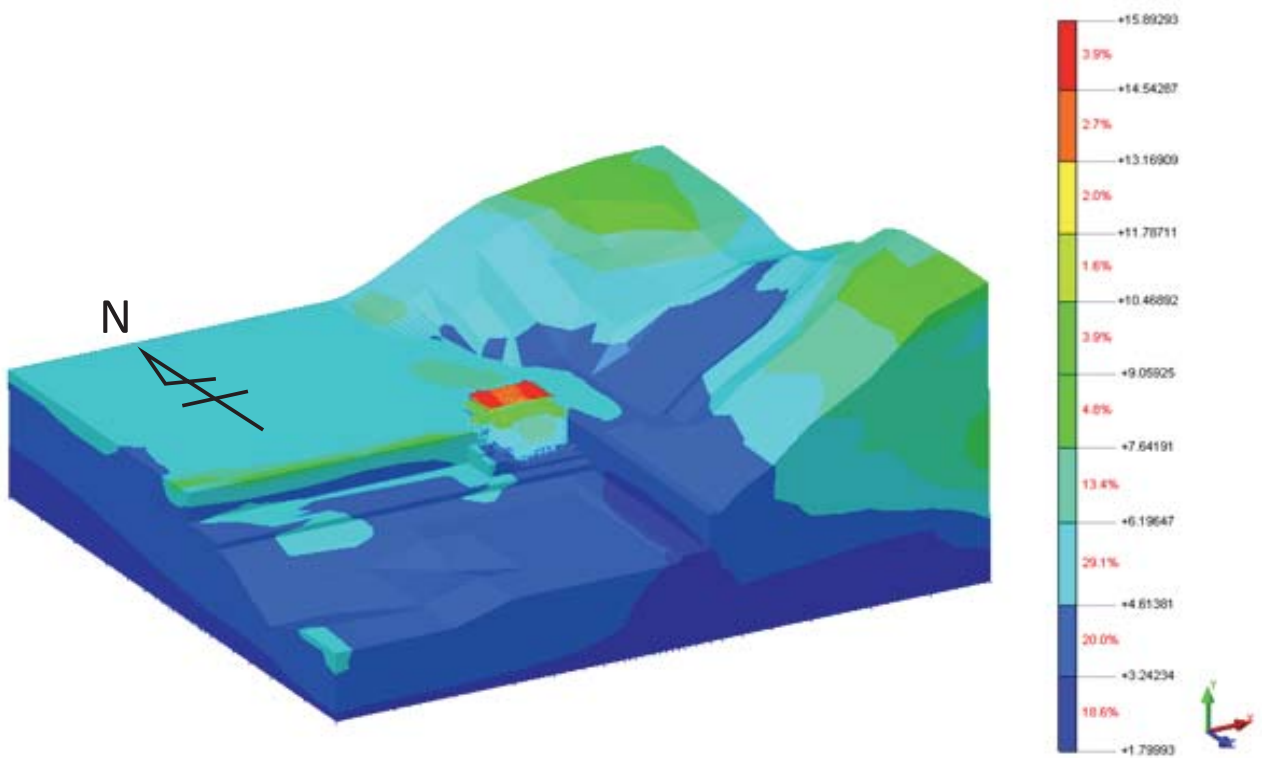

N-S directional component

Figure 18. Distribution of absolute peak response acceleration of the structure and ground coupling model (Single amplitude) (Unit: m/s2) 

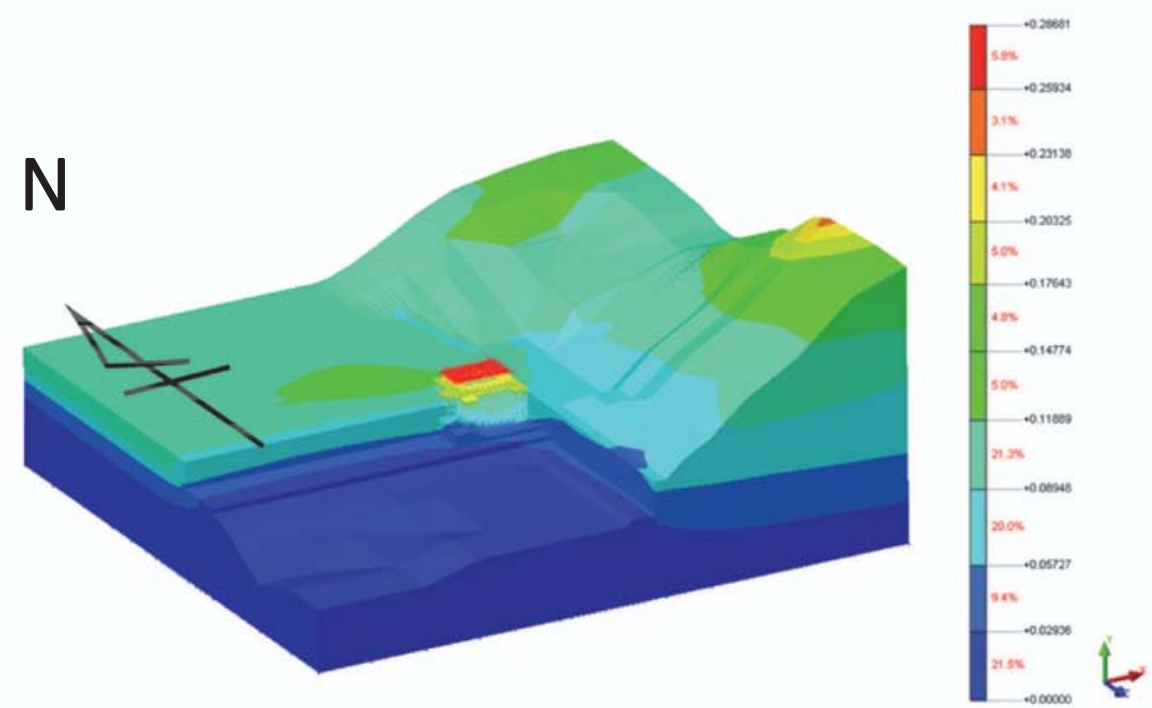

E-W directional component
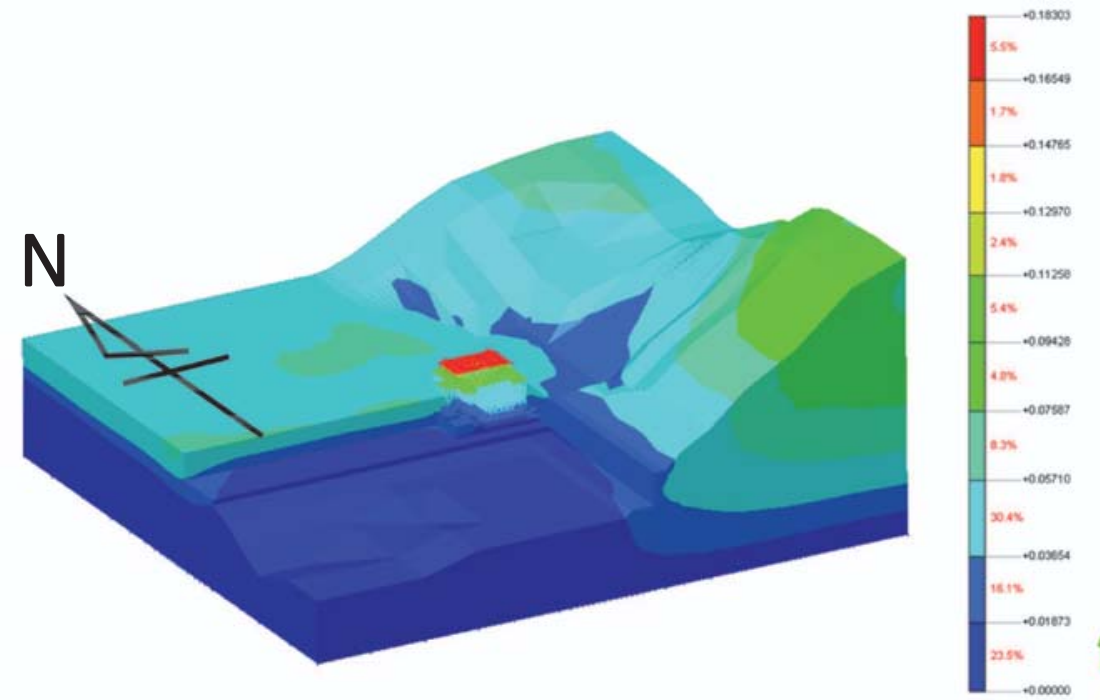

N-S directional component

Figure 19. Distribution of peak response displacement of the structure and ground coupling model (Single amplitude) (Unit: $\mathrm{m}$ )

supporting the stage. For reference purposes, the distribution of the displacement component of E-W and $\mathrm{N}$-S directions, the response accelerations of the ground surface at the main hall (room for enshrined Buddha) and the Fourier spectra are shown in Figs.1820, respectively. As shown in Figs.18, 20 and 21, the peak response accelerations of the ground surface at the main structure are marginally larger than the peak input accelerations of the structure model, but the dominant frequencies of those are reduced to 1.2-1.5 $\mathrm{Hz}$.

\subsection{Seismic evaluation for main wooden structure}

We estimated the damage of the historical main structure based on the maximum inter-story deflection angle of the first floor. Herein, the deflection angle of the damage limit for high-frequency low-impact earthquakes was assumed to be 1/120 radian based on the Japanese Building Standards Act (2011), and that of the safe limit for low-frequency high-impact earthquakes to be 1/30 radian based on the seismic guideline for important cultural properties of the Japanese Agency for Cultural Affairs (2001). The maximum in- 


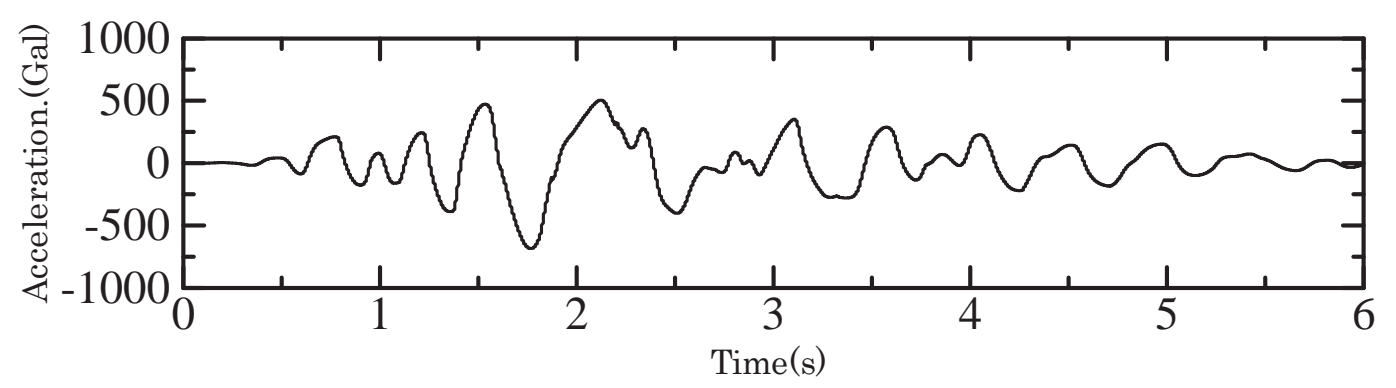

E-W component

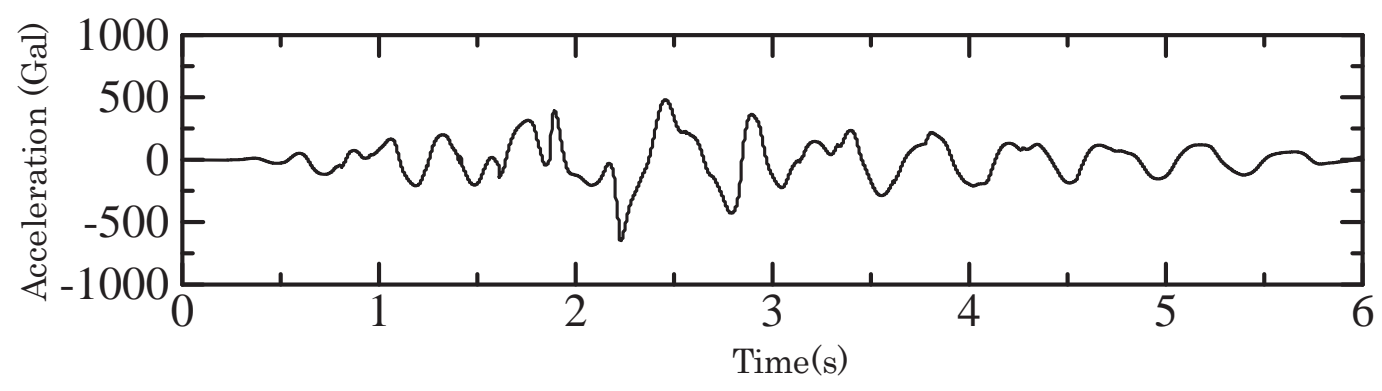

N-S component

Figure 20. Earthquake response acceleration of the ground surface at the main building for the coupling model.

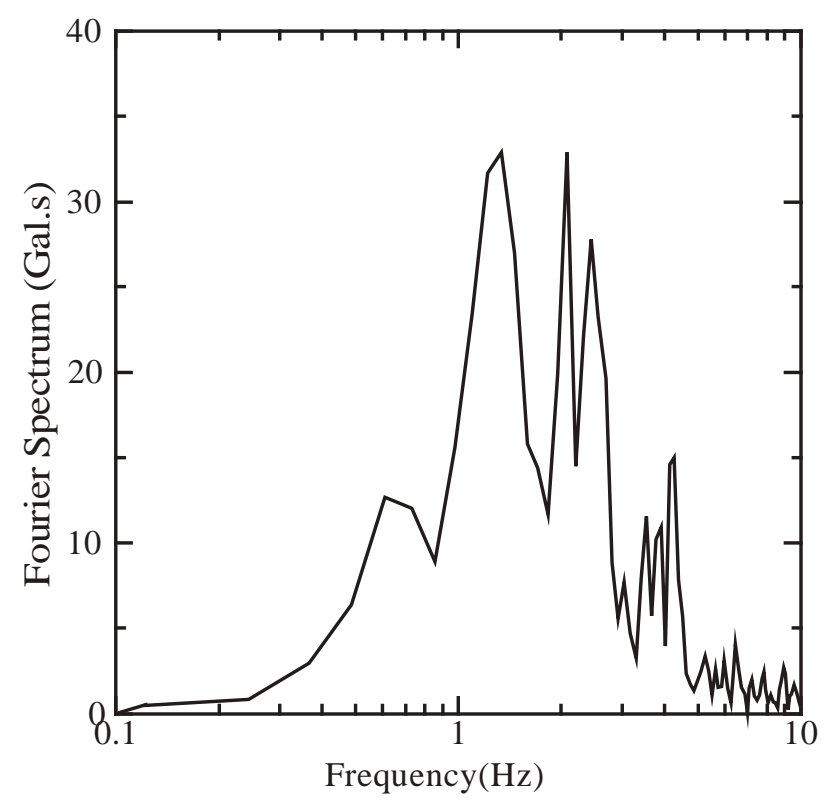

E-W component 


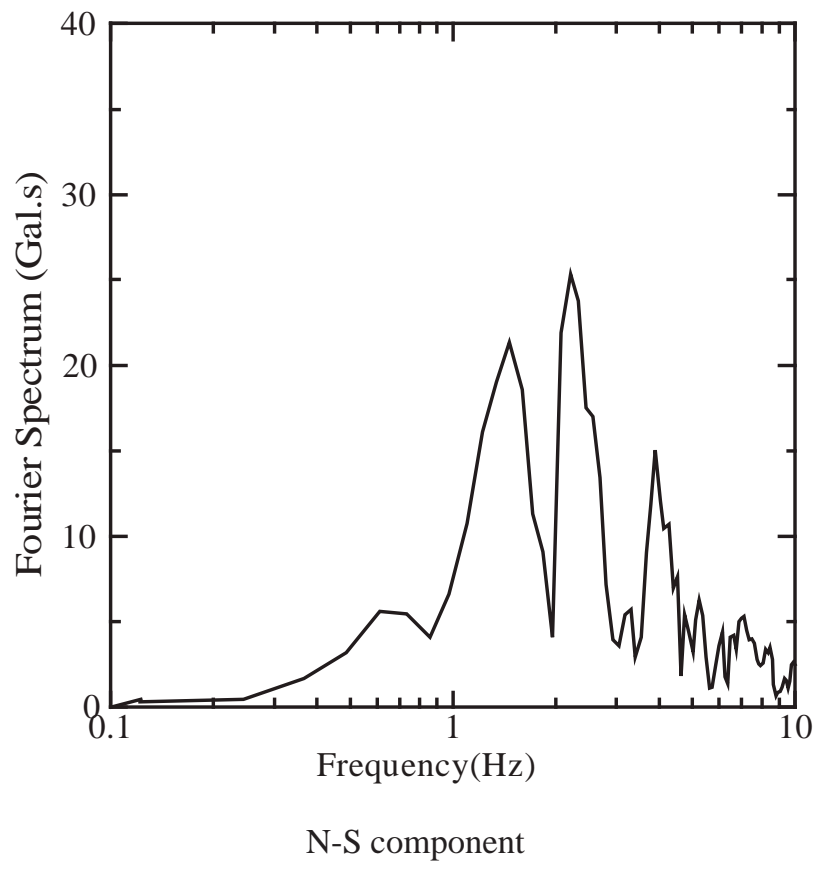

Figure 21. Fourier spectra of the response acceleration of the ground surface at the main building for the coupling model.

ter-story deflection angle was calculated as the relative displacement between the top and the bottom of the support column divided by a height of $4.5 \mathrm{~m}$. The maximum deflection angles of the E-W and the N-S directions at $\mathrm{X} 3$ and $\mathrm{Y} 12$ lines (see Fig.6) are shown in Fig.22. Figure 22 indicates that the inter-story deflection angle on the structure model is $0.5-0.8$ times that on the coupling model. That means that we have the potential to overestimate the seismic safeness of the main structure in the case of the structure model. Non-negligible damage of the main wooden structure, especially in the E-W direction, is anticipated during a scenario earthquake of the Hanaore Fault, because the inter-story deflection angle is estimated to partly exceed the safe limit. The ground motion of the scenario earthquake is not so accurate that we could have double or half the amplitude of the input acceleration. On the condition that we have double the ground motion of the scenario earthquake, the maximum deflection angles of most columns were larger than the safe limit of the structure and the structure was in danger of collapse.

\section{CONCLUSIONS}

We conducted seismic assessment of a main traditional wooden building with a stage based on the three-dimensional non-linear earthquake response analysis for two analytical models against the scenario earthquake from the Hanaore Fault. One model was constructed solely for the main structure (structure model) and the other for the structure and surrounding ground with irregular geometry (coupling model). The salient results obtained from our estimations are as follows:

1. The seismic capacity of the main wooden structure based on the structure model is overestimated, because the inter-story deflection angle of the first floor based on the model is 0.5-0.8 times that of the coupling model. Therefore, it is very important for a valuable structure built on a slope at irregular geometry and in rugged terrain to estimate the seismic safety with the structure-ground coupling model.

2. From the computational results for the coupling model, we estimated that the damage of the main building partly transcends the safety limit during the scenario earthquake. The building stands a risk of collapsing during double the amplitude of the scenario earthquake, because the maximum inter-story de- 


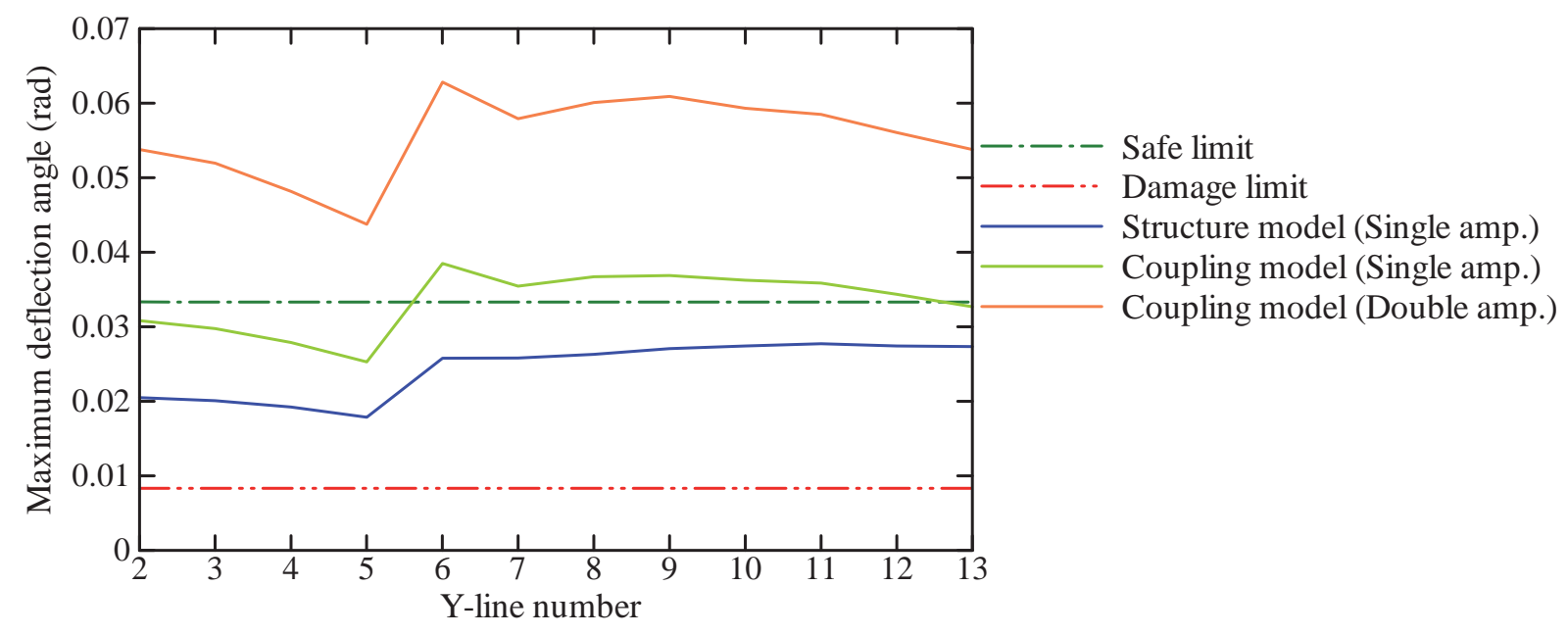

(a) E-W component of X3-line

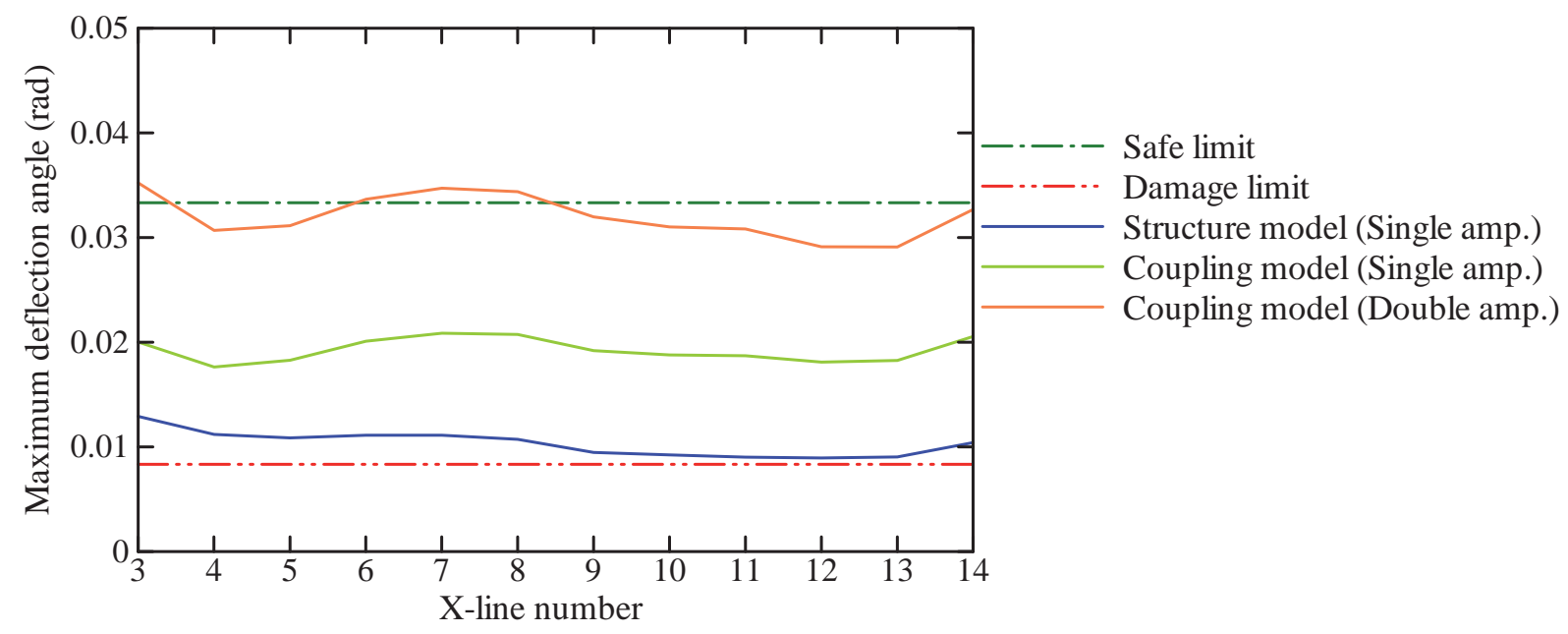

(b) N-S component of Y12-line

Figure 22. Maximum deflection angle of main wooden structure.

flection angles of most of the support columns on the first floor exceeded the safety limit.

\section{REFERENCES}

Architectural Design Data Corpus 10-Technology, 1983. Multiple authors, edited by the Architectural Institute of Japan, Maruzen. (in Japanese)

Architectural Research Association 2007. Report of survey of existing circumstance at main building of Kiyomizu temple and 8 other buildings, 13-31. (in Japanese)

Fujita K, Hanazato T and Sakamoto I., 2004. Earthquake Response Monitoring and Seismic Performance of Five Storied Timber Pagodas, 13th World Conference on Earthquake Engineering, 54, CDR.

Fujita K, Chiba K, Kawai N, Kshihara M, Minowa C and Hanazato T., 2008. Earthquake Response Analysis of Traditional Japanese Timber Pagoda, 10th World Conference on Timber Engineering, CDR.

Kuwata Y, Yamasaki S, Takada S, Toki K and Sunasaka Y., 2009. Seismic evaluation of underground firefighting water pipeline in historical conservation areas, Disaster Mitigation of Cultural Heritage and Cities, 3: 129134. (in Japanese)

Kyoto City Government 2003. The third report of Earthquake Disaster Assessment of Kyoto City. (in Japanese)

Mori Y, Suzuki T, Izuno K and Toki K., 2007. Effect of axi- 
al force fluctuation in supporting columns on earthquake response of traditional wooden Japanese temple, Journal of Japanese Association for Earthquake Engineering, 7(1), 14-21. (in Japanese)

Suzuki T, Kurakata M, Izuno K and Toki K., 2007. Effect of stage on earthquake response of a Japanese traditional wooden structure, Journal of Japanese Association for Earthquake Engineering, 7(5), 15-30. (in Japanese)

Suzuki T, Ishihara T, Sakamoto D, Izuno K and Toki K., 2005. Static and dynamic characteristics of Japanese traditional wooden temple structure with stage, Journal of Sociotechnology Research Network, 3: 175-185. (in Japanese)

The Building Center of Japan 2011. The Building Standard Law of Japan.
The Ministry of Education, Culture, Sports, Science \& Technology in Japan 2001. Fundamental Assessment Manual Based on the Seismic Guideline for Important Cultural Properties of the Japanese Agency for Cultural Affairs. (in Japanese)

Toki K, Kishimoto H, Furukawa H and Sakai H., 2007. Strong ground motion prediction based on 3-dimensional non-elastic FEM in Kyoto Basin area from a scenario earthquake of the Hanaore Fault, Journal of Japan Association for Earthquake Engineering, 7(5), 45-59. (in Japanese)

Toki K., Izuno K and Fukagawa R. 2013. Earthquake response of Japanese traditional wooden structure on a hillside considering interaction between surrounding ground, 32(1), 103-115 (in Japanese) 